\title{
The role of HPV-induced epigenetic changes in cervical carcinogenesis (Review)
}

\author{
MARTHA LAYSLA RAMOS DA SILVA ${ }^{1,2}$, BEATRIZ HELENA DANTAS RODRIGUES DE ALBUQUERQUE ${ }^{3}$, \\ THALES ALLYRIO ARAÚJO DE MEDEIROS FERNANDES ${ }^{4}$, VALÉRIA DUARTE DE ALMEIDA ${ }^{4}$, \\ RICARDO NEY DE OLIVEIRA COBUCCI ${ }^{5}$, FABIANA LIMA BEZERRA ${ }^{1}$, VANIA SOUSA ANDRADE ${ }^{1,2}$, \\ DANIEL CARLOS FERREIRA LANZA ${ }^{3}$, JENNER CHRISTIAN VERÍSSIMO DE AZEVEDO ${ }^{6}$, \\ JOSÉLIO MARIA GALVÃO DE ARAÚJO ${ }^{1,2}$ and JOSÉ VERÍSSIMO FERNANDES ${ }^{1,2}$ \\ ${ }^{1}$ Department of Microbiology and Parasitology; ${ }^{2}$ Post-Graduate Program in Parasite Biology; \\ ${ }^{3}$ Laboratory of Applied Molecular Biology, Department of Biochemistry, Federal University of Rio Grande do Norte, Natal \\ 59078-970; ${ }^{4}$ Department of Biomedical Sciences, State University of Rio Grande do Norte, Mossoro 59607-360; \\ ${ }^{5}$ Department of Gynecology and Obstetrics, Potiguar University, Natal 59056-000; \\ ${ }^{6}$ Department of Pediatrics, Federal University of Rio Grande do Norte, Natal 59012-570, Brazil
}

Received November 12, 2020; Accepted March 10, 2021

DOI: $10.3892 / b r .2021 .1436$

\begin{abstract}
Cervical cancer is associated with infection by certain types of human papillomaviruses (HPVs), and this affects women worldwide. Despite the improvements in prevention and cure of HPV-induced cervical cancer, it remains the second most common type of cancer in women in the least developed regions of the world. Epigenetic modifications are stable long-term changes that occur in the DNA, and are part of a natural evolutionary process of necessary adaptations to the environment. They do not result in changes in the DNA sequence, but do affect gene expression and genomic stability. Epigenetic changes are important in several biological processes. The effects of the environment on gene expression can contribute to the development of numerous diseases. Epigenetic modifications may serve a critical role in cancer cells, by silencing tumor suppressor genes, activating oncogenes, and exacerbating defects in DNA repair mechanisms. Although cervical cancer is directly related to a persistent high-risk HPV infection, several epigenetic changes have been identified in both the viral DNA and the genome of the infected cells: DNA methylation, histone modification and gene silencing by non-coding RNAs, which initiate and sustain epigenetic changes. In the present review, recent
\end{abstract}

Correspondence to: Dr Thales Allyrio Araújo de Medeiros Fernandes, Department of Biomedical Sciences, State University of Rio Grande do Norte, Rua Miguel Antônio da Silva Neto, S/N, Bairro, Aeroporto, Mossoro, Rio Grande do Norte, Natal 59607-360, Brazil

E-mail: thalesallyrio@uern.br

Key words: cervical cancer, HPV-induced carcinogenesis, epigenetic changes, DNA methylation, non-coding RNA advances in the role of epigenetic changes in cervical cancer are summarized.

\section{Contents}

1. Introduction

2. Methods

3. Epigenetics

4. The role of ncRNAs in HPV-induced UCC

5. Conclusions

\section{Introduction}

Uterine cervix cancer (UCC) is classed as the fourth most common type of cancer that occurs uniquely in women, and constitutes a serious global public health problem (1). With an estimated occurrence of 528,000 new cases in 2012 and an overall incidence rate of 14/100,000 women, UCC is the second most common type of cancer diagnosed and the third leading cause of cancer-associated death in women in the least developed countries (2,3). In Brazil, UCC is third in prevalence, excluding non-melanoma skin cancer (statistics for which may be incomplete), after breast and colorectal cancer. The incidence of UCC has remained stable over the last 5 years, with an estimated average risk of 15.57/100,000 women between 2014 and 2018 (4).

Virtually all UCC cases are triggered by persistent infection of the uterine cervix by human papillomavirus (HPV) high risk genotypes, particularly HPV16 and HPV18 $(5,6)$. However, it is known that the virus alone is not sufficient to cause this malignant disease (7). Thus, additional factors are necessary for the progression of a low-grade squamous intraepithelial lesion to a high-grade lesion, and consequently to invasive cancer (8). Dysregulation of both viral and host 
gene expression due to viral DNA integration into the cell's genome, as well as epigenetic modifications are crucial events in the carcinogenic process (7). In addition, high-risk HPV infection can lead to aberrant expression of oncogenic and tumor suppressor micro RNAs (miRNAs), most of which have either c-Myc, p53 or E2F transcription factors as downstream targets, and whose expression can be modulated by the E6 and E7 viral oncoproteins (9).

The unresolved long-term chronic inflammation caused by HPV creates a microenvironment where complex interactions involving cytokines, chemokines, free radicals, prostaglandins, growth factors and enzymes, such as cyclooxygenase and matrix metalloproteinases (MMPs) may also induce genetic and epigenetic changes, affecting critical signaling pathways for maintenance of cellular homeostasis (10).

Several epigenetic changes were identified during HPV infection in both virus and host cell genomes, including hypomethylation or hypermethylation of viral DNA and hypermethylation of host cell tumor suppressor genes, as well as histone modifications and changes in expression of non-coding RNAs (ncRNAs) (11). The E6 and E7 viral oncoproteins interact and/or alter the expression of several cellular proteins involved in epigenetic regulation, altering the transcriptional competence of the infected cells caused by the changes in gene expression, increased activity of histone-modifying enzymes and chromatin remodeling $(11,12)$. It has been observed that the loss of control of expression of E6 and E7 genes during HPV infection is caused by the rupture of the E1 and/or E2 viral genes during integration of the viral DNA into the host cell genome or due to the hypermethylation of the virus' early promoter DNA, which is located in the long control region (LCR) of the viral genome that regulates the expression of these genes (13).

The LCR is a non-coding sequence of the HPV genome responsible for regulating the expression of viral genes. The early and late promoters of these genes, as well as the binding sites of viral proteins E1 and E2, and several transcription factors of the host cell, are located in this region of the viral genome. The E2 protein is the major intragenomic regulator of the virus and modulates the expression of the viral E6 and E7 oncogenes by binding to the E2BS site located in the LCR. The E2 binding site has $\mathrm{CpG}$ islands with potential for methylation, which results in the inhibition of its transcriptional regulatory function of the E6 and E7 genes, leading to overexpression of these viral oncogenes $(13,14)$.

In the present review, recent advances in our understanding of the role of epigenetic changes in the process of cervical carcinogenesis induced by high-risk HPV infections in the initiation, progression and invasion of cervical cancer are summarized.

\section{Methods}

The present literature review was performed using PubMed (National Institutes of Health; ncbi.nlm.nih.gov/pubmed), Scopus (Elsevier; scopus.com/scopus/home.url) and Web of Knowledge (Thomson Reuters; wok.mimas.ac.uk) electronic databases, and the following key words were searched: 'Epigenetics', 'Cervical cancer', 'HPV-induced carcinogenesis', 'Regulation of genetic expression in cervical cancer',
'Epigenetic changes in cervical cancer', 'DNA Methylation in cervical cancer', 'Modifications of histones in cervical cancer', and 'Non-coding RNA in cervical cancer'. Several hundred articles were found in the surveyed databases, and only the most relevant ones, published in high-impact factor journals, and conducted by groups with recognized knowledge in the area were selected.

\section{Epigenetics}

Epigenetic modifications are inherited characteristics that are not caused by changes in the DNA sequence, as they result from changes in gene expression due to changes in DNA accessibility or chromatin structure (15). They are reversible modifications in gene function, involving overexpression or silencing of genes by mechanisms that do no result in DNA alterations, therefore being responsible for changes in the phenotype without genotypic alterations $(16,17)$.

Such changes are caused by methylation or acetylation of DNA, post-translational modification of histones, or by the action of ncRNAs, which can be triggered by exogenous and environmental factors that regulate the differentiation and development of cells and organs (15). They are normal events of regular occurrence that can be influenced by several factors including age, environment, lifestyle, cellular stress and pathological factors (18-20).

Although epigenetic modifications are a natural adaptation mechanism to changes in the environmental conditions, the complex regulation of gene expression promoted by these modifications can lead to detrimental consequences in the organism causing an inverse effect to what is expected, resulting in accumulation of characteristics that diminish its adaptability, which in-turn leads to pathological conditions, such as cancer (21). The epigenetic modifications may serve a critical role in cancer cells, promoting silencing of tumor suppressor genes, activation of oncogenes and defects to DNA repair mechanisms (22). Such alterations may subvert the controlled division of healthy cells through different molecular pathways, leading to unlimited capacity for division, genomic instability, metabolic displacement, and acquisition of characteristics of mesenchymal cells by increased survival and displacement to distant sites from the original tissue (23). At least three systems including DNA methylation, histone modification, expression or silencing of ncRNA encoding genes are currently considered the primary systems responsible for initiating and supporting epigenetic changes (24).

The tumorigenic process involves changes in the transcriptional pathways of cells that lead to reprogramming with remodeling of the $3 \mathrm{D}$ structures of the genome, which is used by cancer cells to initiate tumors. This reprogramming is triggered by hereditary chemical modifications of chromatin that result in the formation of RNA-protein-DNA complexes that serve as the primary factors responsible for the dysregulation of gene expression, and this may be a cause and a consequence of cancer-related epigenetic alterations (24).

Although UCC is directly related to a persistent high-risk HPV infection, several epigenetic changes have been identified in both the viral DNA and the genome of infected cells. Hypermethylation of the E2 binding site located in the LCR of the viral genome, hypomethylation of the overall DNA and 
hypermethylation of host cell tumor suppressor genes have been reported. In addition, histone modifications and acetylation, and changes in ncRNA expression patterns are involved in the carcinogenic process (11). Some aspects of these epigenetic mechanisms in the initiation and progression of UCC are discussed below.

Methylation of DNA. Methylation is the replacement of a hydrogen atom by a methyl group by means of covalent attachment at the Carbon 5 position, predominantly of the nucleoside cytosine, preceding the guanine nucleotide $(\mathrm{CpG})$ catalyzed by DNA methyltransferase (DNMT) enzymes (25). The methylation levels in the $\mathrm{CpG}$ islands of regulatory gene promoters serve as an epigenetic mechanism used by cells to regulate gene expression (26). Methylation of the promoter region of a gene generally results in its silencing, whereas demethylation leads to an increase in its expression (27). This epigenetic mechanism evolved to allow regulation of several biological processes aiming to maintain homeostasis in situations of cellular stress. Thus, when these mechanisms are deregulated for any reason, it may result in the development and progression of several diseases, particularly cancer (28).

DNA methylation in normal cells is involved in regulating gene expression, including chromatin organization (29). In contrast, global hypomethylation of DNA in tumor cells is observed in repetitive regions and hypermethylation in $\mathrm{CpG}$ islands of tumor suppressor gene promoters, as well as increased maintenance of DNMT1 activity $(30,31)$.

The carcinogenic process of UCC is related to several epigenetic mechanisms, including the hypermethylation of the promoters of regulatory genes, which can result in the activation of oncogenes and inactivation or loss of function of tumor suppressor genes, additionally affecting the expression of HPV genes, a primary risk factor of the disease (Fig. 1) (32).

However, the role of DNA methylation in silencing tumor suppressor genes and its implications in the development of diseases varies according to the ethnic characteristics of the population. A meta-analysis of 15 studies covering a total of 950 UCC samples and 829 controls showed that methylation of the CDH1 gene promoter which encodes cadherin 1, a protein involved in adhesion between cells, is associated with an increased risk of UCC in Caucasian women, but not in Asian women (33). In addition to its role in the initiation and progression of UCC, DNA methylation status can also be used as a molecular marker for detection of cervical cancer, from cervical scrapes and even in the urine. Although the cervical scrapes showed better results, urine showed a significant increase in levels of six of the methylation markers assessed, when compared to the healthy controls, showing that this may be a promising strategy for the detection of cervical cancer (34).

Cell DNA methylation. A wide range of cellular genes, particularly those involved in cell cycle regulation, apoptosis, DNA damage repair and cell adhesion, senescence and survival of cells, including TP53 and RB1 tumor suppressor genes, are altered in UCC due to aberrant methylation patterns of their promoters caused by the action of the oncoproteins encoded by the E6 and E7 genes of high-risk HPVs $(6,35,36)$. In HPV-infected cells expressing high levels of E6 and E7 viral oncoproteins, there is a subversion of cell cycle control and DNA repair mechanisms, as well as inhibition of senescence and cell death by apoptosis (37). In addition, these viral proteins also contribute to immune evasion by inhibiting interferon-signaling pathways, reducing the ability of antigen presentation and inducing tolerance of T cells (38). E6 and E7 viral oncoproteins act together to promote the hypermethylation of cellular genes. E6 promotes degradation of $\mathrm{p} 53$ and release of Sp1 transcription factors, which binds to the DNMT1 gene promoter, activating its expression. On the other hand, E7 forms a stable complex with $\mathrm{pRB}$, releasing the transcription factor E2F, which binds to the DNMT1 gene promoter, activating its expression. Both mechanisms lead to production of DNA methyl transferase enzymes, which promotes the hypermethylation of $\mathrm{CpG}$ islands and the silencing of cellular genes (6).

The Wnt- $\beta$-catenin signaling pathway is involved in regulating the differentiation, proliferation, migration and differentiation of cells. Therefore, dysregulation of this pathway is associated with several types of cancer, including UCC. High-risk HPVs, through their E6 and E7 oncoproteins, can activate the Wnt- $\beta$-catenin pathway via several mechanisms. E6 and Dvl, both cell proliferation regulatory proteins, bind to $\beta$-catenin and promote its stabilization by increasing the transcriptional activity of TCF, which prevents the phosphorylation of $\beta$-catenin and its degradation. E6 can also protect $\beta$-catenin from degradation by binding to the E6PA protein of the infected cell. In addition, E6 and E7 bind to the catalytic subunit of protein phosphatase 2 (PP2A) to inhibit the phosphorylation of $\beta$-catenin by preventing its degradation and promoting its stabilization in the cytoplasm. Thus, transformation and carcinogenesis of human keratinocytes induced by HPV requires activation of the Wnt- $\beta$-catenin, contributing to the proliferation and invasion of tumor cells (39).

The silencing by hypermethylation of the A-1 gene promoter of the Adenomatous polyposis coli $(A P C)$, whose product is a negative regulator that controls $\beta$-catenin via interaction with E-cadherin, results in the abnormal accumulation of $\beta$-catenin in cell lines infected with HPV16. Together, $\beta$-catenin and E-cadherin participate in several prominent oncogenic mechanisms in various types of cancer that are associated with aberrant activation of Wnt- $\beta$. Demethylation of the A-1 gene promoter results in increased APC expression levels and reduced $\beta$-catenin expression, acting on two transcriptional targets of the Wnt- $\beta$-catenin pathway: Matrix-7 metalloproteins and vascular endothelial growth factor. This suggests that APC gene silencing by hypermethylation of its promoter is involved in HPV-induced carcinogenesis by promoting activation of Wnt- $\beta$-catenin (40).

The transcriptional silencing via $\mathrm{CpG}$ island hypermethylation of the KIPI and TP53 promoter genes encoding the p27 and p53 proteins, respectively, both involved in cell cycle regulation, is strongly associated with UCC when compared with normal tissue (41). A similar process occurs with the hypermethylation of the phosphatase and tensin homolog gene promoter, which is also involved in the regulation of cell cycle progression, resulting in the silencing of this tumor suppressor gene. Reduced expression of these genes is correlated with increased proliferation and cell motility via inactivation of the PI3-kinase-dependent signaling pathway (42).

The negative regulation by hypermethylation of the RASSF1 promoter gene, which is involved in the activation of the signaling 


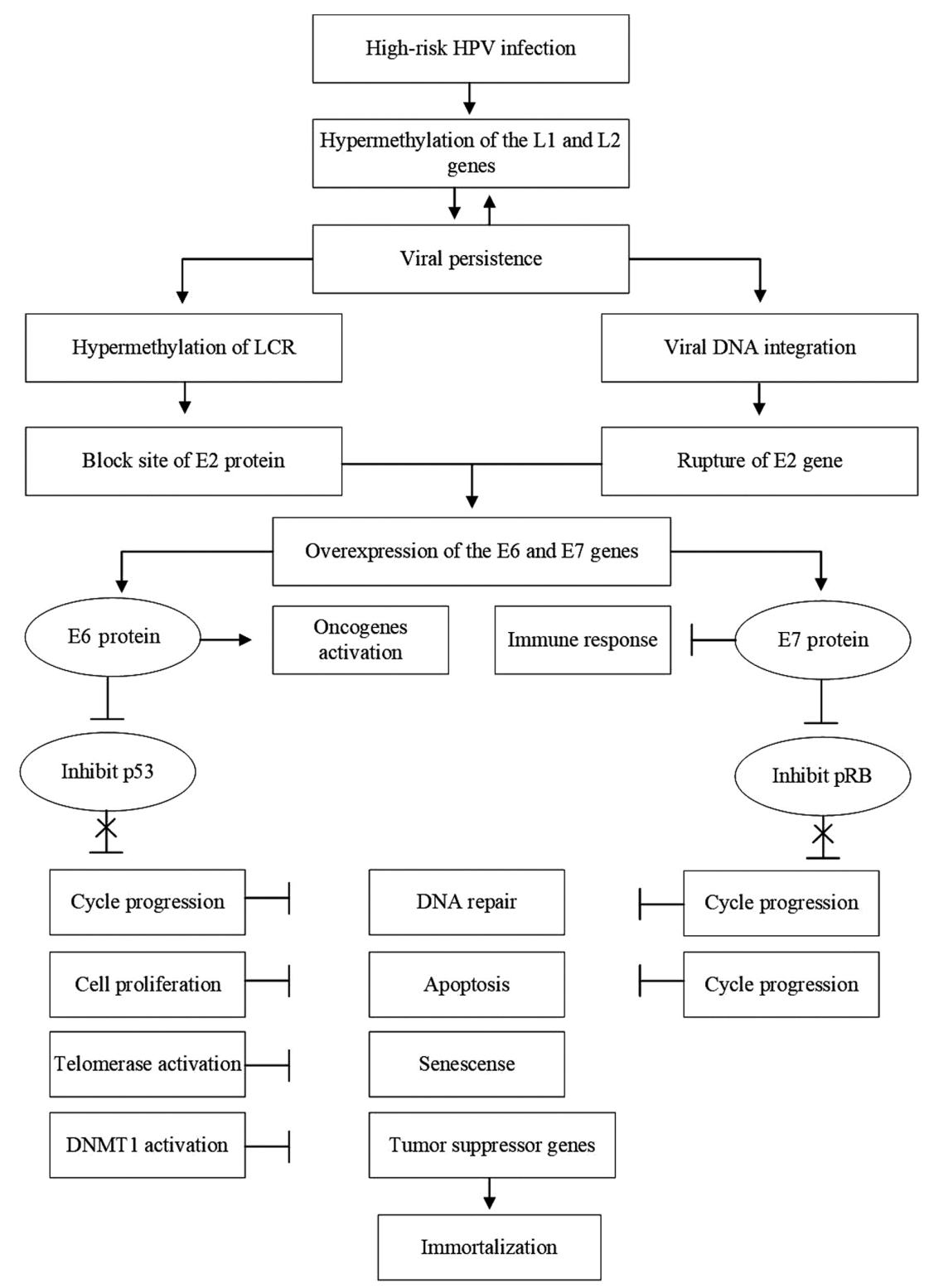

Figure 1. The role of epigenetic changes in the development of UCC. The process begins with infection of the epithelium that lines the cervix with high-risk HPVs. During productive HPV infection, methylation of the L1 and L2 late viral genes may occur, increasing the risk of viral persistence. Viral persistence favors the methylation of both viral and cellular DNA, also increasing the risk of malignant transformation of the infected cell. Hypermethylation of the LCR of the viral genome blocks the binding site of the viral E2 protein to this region, preventing its regulatory function on the expression of the viral oncogenes E6 and E7, whose products are directly associated with carcinogenesis. Another crucial event in this process is the integration of the viral DNA into the cell genome, which results in the rupture of the viral E2 gene, interrupting the production of the E2 protein and abolishing its regulatory function on the expression of the viral genes E6 and E7, leading to overproduction of viral oncoproteins. E6 protein can act directly by activating the expression of oncogenes or inducing the degradation of the tumor suppressor protein p53, resulting in progression of the cell cycle, preventing DNA repair, increasing cell proliferation, and inhibiting apoptosis. In addition, E6 activates telomerase, prevents cell senescence and activates DNA methyltransferase, which favors the methylation of cellular and viral genes, and promotes the silencing of tumor suppressor genes. Conversely, E7 can act directly by inhibiting the host's immune response, interfering with the presentation of antigens, interferon signaling pathways and maturation of T lymphocytes, as well as increasing the tolerance to these T-cells. In addition, E7 induces degradation or inhibition of the function of the cell's tumor suppressor pRB protein, which results in cell cycle progression, inhibition of DNA repair mechanisms and uncontrolled cell proliferation. Thus, the joint action of viral proteins E6 and E7 leads to the immortalization of cells infected by HPV, followed by the malignant transformation of these cells. UCC, uterine cervix cancer; HPV, human papillomavirus; LCR, long control region; DNMT1, DNA methyltransferase 1.

pathway, which inhibits cell proliferation and induces apoptosis, has been shown in numerous studies to increase the risk of UCC (43). A similar outcome is observed following silencing of the $C D K N 2 A$ gene by hypermethylation of its promoter. The $C D K N 2 A$ gene encodes the p16INK4a tumor suppressor protein, which interacts with cyclin dependent kinases, CDK4 and CDK6. This interaction prevents $\mathrm{pRB}$ phosphorylation with E2F release, leading to cell cycle arrest in the G1 phase (44). Thus, $C D K N 2 A$ silencing by hypermethylation of its promoter results in the phosphorylation of $\mathrm{pRB}$ with the release of $\mathrm{E} 2 \mathrm{~F}$, which in-turn activates gene transcription, in-turn promoting cell cycle progression resulting in cell immortalization, and thus contributing to the pathogenesis of $\operatorname{UCC}(6,45)$.

Hypermethylation of the $C D H 1$ gene promoter, is associated with HPV-induced carcinogenesis, as silencing of this gene increases the risk of worsening cervical lesions. In addition, the increased methylation density of this gene is associated with UCC progression and metastasis, and has been 
suggested as a possible epigenetic marker that can be used to predict the risk of disease progression (46).

In a meta-analysis study, four genes were identified as common targets for aberrant methylation in UCC including the death-associated kinase protein-1 gene, which activates IFN- $\gamma$ and induces apoptosis; the retinoic acid receptor $\beta(\operatorname{RAR} \beta)$ gene, which induces vitamin A production and is associated with cell growth and differentiation; the Wnt- $\beta$ inhibitory factor gene, whose product inhibits the Wnt- $\beta$-catenin signaling pathway; and the slit-orientation ligand gene 2 , which is associated with cell migration, all of which are silenced in UCC. The hypermethylation of the promoters of these four genes occurs early in cervical carcinogenesis and appears to be specific to UCC (47).

Hypermethylation of promoters EPB4L3 and FAM19A4 cell genes encoding a cell adhesion molecule and a cytokine that attracts and enhances the phagocytic activity of macrophages, respectively, is associated with an increased risk of UCC (48). Other cellular genes, such as ADCYAP1, MAL (a T-cell differentiation protein) and $C A D M 1$ are also silenced in cells derived from UCC, due to hypermethylation of their promoters, and this condition is associated with a greater risk of tumor progression (49). Moreover, PAX1 cell genes, which encode the transcription factor paired box 1, SOXI for the sex determining region Y-box 1 and $L M X 1 A$ for LIM homeobox transcription factor $1 \alpha$, all of which are involved in controlling cell division and differentiation, showed significantly higher methylation levels of their promoters in UCC cells when compared to normal cervical tissues (50,51). Finally, the $R A R \beta$ gene, which is usually expressed in normal epithelial tissue, acts as a tumor suppressor when interacting with its ligand to inhibit cell migration (52).

In some cases, an inverse situation is observed in which activation of oncogene expression by demethylation of its promoters contributes to cervical carcinogenesis. For example, serine/threonine kinase 31 (STK31) gene expression has been shown to be regulated by demethylation of its promoter and serves a crucial role in several types of cancer, increasing migration and invasiveness without altering the proliferation of cancer cells (53). The STK31 gene promoter was found to be hypomethylated in the SiHa cell line positive for high-risk HPV 16, and in the CaSki and HeLa cell lines positive for high-risk HPV 18, and its expression was increased at both the mRNA and protein level. In contrast, the $S T K 31$ promoter was hypermethylated, which resulted in silenced expression in the C33A and HT-3 cell lines, both of which are derived from UCC, but are HPV-negative. It is hypothesized that the E7 oncogene of high-risk HPVs activates the expression of STK31 by promoting the demethylation of its promoter, causing overexpression of this gene, leading to an increase in the invasive capacity of cancer cells (53). In addition, the analysis of the methylation patterns of region 1 of the human telomerase reverse transcriptase ( $h T E R T)$ gene from 93 positive samples and 15 distinct HPV types revealed differences in methylation patterns of this gene for different viral genotypes. A positive association was identified between high-risk HPVs of the $\alpha 7$ and $\alpha 9$ subtypes, and absence of methylation of the hTERT gene promoter, indicating that it was being expressed (54).

HPV genome methylation. Studies have shown that epigenetic changes in the HPV genome, particularly methylation, not only serves an important role in the replicative cycle of the virus, but also in the progression of low- and high-grade cervical intraepithelial lesions in HPV-associated invasive cancer $(55,56)$. It has been found that methylation of $\mathrm{CpG}$ islands of the E2 viral protein binding site, located in the LCR viral genome and promoters of the late genes, may abolish the E2 regulatory function or silence the expression of the $L 1$ and $L 2$ late genes, thus contributing to HPV-induced carcinogenesis (55). It has also been observed that LCR methylation is more frequent in UCC than in cervical intraepithelial neoplasia (CIN). In addition, it was found that the hypermethylation of $\mathrm{CpG}$ islands of LCR of the PV16 increases with the severity of cervical lesions, being significantly higher in invasive cancer (57).

High-risk HPV-induced carcinogenesis is primarily caused by the overexpression of the E7 and E6 viral oncoproteins after integration of the viral DNA into the host cell genome and concomitant loss of the E2 viral protein regulatory function, due to rupture and inactivation of that $E 2$ gene that occurs during integration. Therefore, the viral genome in most of the UCC cells is in the integrated form (58). However, in part of the tumor cells, the viral genome is found in the episomal form, but presents with methylated promoters. This is due to the fact that the methylation of the E2BS site of the LCR of the viral genome prevents binding of the E2 protein to its target sequence, preventing its regulatory action. This leads to overexpression of $E 6$ and $E 7$ viral oncogenes, creating a condition similar to what occurs after integration of viral DNA into the cell genome, and also resulting in carcinogenesis $(14,58)$.

The analysis of LCR methylation levels of three different high-risk HPV types (16, 18 and 45) in 137 samples of UCC tissues positive for HPV revealed that HPV16 showed a higher methylation density in all $\mathrm{CpG}$ islands of the LCR. The presence of intact E1 and E2 was associated with higher levels of methylation on all CpG islands of both HPV16 and HPV18. $E 1$ and/or E2 gene rupture was observed more frequently in the genomes of HPV18 and HPV45, compared with HPV16. E1 gene rupture was more frequent in HPV16, whereas E2 gene rupture was more frequent in HPV18. A positive association was found between higher methylation levels of the LCR and absence of disruption of E1 or E2 genes for HPV 16 and 18. HPVs 18 and 45 are highly phylogenetically related, and showed similar levels of methylation, with the same being observed in relation to E2 gene rupture (13).

Methylation levels of the HPV genome, particularly in the late L1 and L2 genes, vary during the viral replication cycle, as well as during the different stages of HPV-associated cervical lesions (55). Methylation of the LCR seems to be correlated with persistent infection, as when it is demethylated, the E1 and E2 proteins bind to the origin of replication and initiate viral replication $(59,60)$. The $\mathrm{E} 2$ protein acts during the productive cycle of the infection, activating the duplication of viral DNA and synchronizing the DNA duplication of the virus with the cell DNA to guarantee the passage of a copy of the viral genome to the daughter cells during cell division. In persistent infection, the E2 protein is expressed in the suppressor isoform $\left(E 8^{\wedge} \mathrm{E} 2\right)$, which functions as a negative regulator of viral replication, since it represses the expression of early genes, particularly E6 and E7 $(58,60)$. Both E2 activities are affected by hypermethylation of its binding site, E2BSs located in the LCR of the viral genome (61).

Evidence indicates that hypermethylation of the L1 late gene of HPV16 is associated with a greater likelihood of developing 
persistent infection. A recent study compared the methylation status of the $L 1$ gene from HPV 16 samples isolated from women with transient and persistent infection. It was revealed that the methylation status of the viral genome at position 5,962 , corresponding to the $L 1$ gene was significantly higher in samples of the virus isolated from women with persistent infection compared with those isolated from women with transient infection. This suggests that hypermethylation of the $L 1$ gene of HPV16 is associated with viral persistence (62). A similar result has also been reported in another study, in which a high level of methylation was found in several CpG islands of the $L 1$ gene of HPV16 and this condition was shown to be associated with an increased risk of persistent infection by HPV16 (63).

It was found that the degree of $L 1$ gene methylation of HPV 16,18 and 52 is associated with the severity of cervical lesions associated with high-risk HPV genotypes. In addition, it was found that the methylation of the $L 1$ gene promoter of HPV 16 and 18 was positively correlated with the degree of methylation of the host genes, such as $P A X 1$ and SOX1 (64). PAX1 is a tumor suppressor that regulates cell division and differentiation, methylation and silencing of which is strongly associated with the progression of premalignant lesions to UCC (65). SOX1 is a tumor suppressor that is related to cell division and differentiation, and it is also associated with cell growth and invasion in UCC by interfering with the Wnt- $\beta$-catenin pathway. Therefore, the silencing of $P A X 1$ and $S O X 1$ by methylation of their promoters favors tumor development (66).

A study found that $\mathrm{CpG}$ island methylation was significantly more prevalent in the $L 1$ gene promoter than in the LCR of the HPV 16, 18 and 51 genomes. The intensity of DNA methylation in the HPV 16 gene promoter L1 was correlated with the severity of cervical injuries $(56,67)$. Methylation was detected in $13 \mathrm{CpG}$ islands of the $L 1$ gene of HPV 16 , with a gradual increase in methylation density proportional to the severity of the lesions. This suggests an association between L1 gene methylation and viral persistence, contributing to the progression of pre-malignant lesions to cervical cancer (63). It was found that the methylation density of the $\mathrm{CpG}$ islands of the L1 gene promoters of HPV16 and HPV18 increased according to the severity of lesions. Methylation of the $\mathrm{CpG}$ islands at position 5,608 of the $L 1$ gene of HPV16 was associated with all degrees of cervical intraepithelial lesions, whereas methylation of $\mathrm{CpG}$ islands at position 5,617 was shown to be more strongly associated with invasive cancer (68).

In a recent case-control study, the degree of methylation of CpG islands within the late $L 1$ and $L 2$ gene promoters of 12 different types of high-risk HPVs was evaluated in a total of 30 cases of precancerous lesions and 30 control HPV-infected cases without precancerous lesions. It was found that the methylation density of $L 1$ and $L 2$ genes was positively correlated with the presence of grade-3 CIN and in situ adenocarcinoma for all $12 \mathrm{HPV}$ types tested. The authors concluded that methylation of HPV DNA is a general phenomenon that marks the transition from HPV infection to pre-malignant lesions and proposed the development of a combined multiple-methylation assay that could be used as a screening test for HPV-positive women to evaluate the risk of lesion progression (69).

Histone modifications. In general, transcriptionally active genes are characterized by promoters with dinucleotides and nucleosomes with their unmethylated $\mathrm{CpG}$ islands. However, DNA methylation does not only affect gene expression, as epigenetic regulation of gene expression can also be influenced by histone modifications and remodeling of nucleosomes (70). Post-translational modifications of histone tails, such as acetylation, methylation, phosphorylation, sumoylation and ubiquitination affects the physical state and the transcriptional competence of the chromatin. These changes in chromatin are crucial in regulating cellular processes, including stem cell maintenance, cell differentiation and cell fate, as well as cell cycle control and epigenetic heritability of transcription programs $(11,71)$.

Reduction of the levels of histone acetylation serves an essential role in the neoplastic process through the epigenetic silencing of tumor suppressor genes. Thus, inhibition of histone deacetylase enzymes (HDACs) has become a promising approach in cancer therapy (72). Transcriptionally active genes generally have high histone acetylation levels marked by low levels of trimethylation of lysine residues of certain histones, as well as histone H2B ubiquitylation. In contrast, transcriptionally inactive genes are characterized by low acetylation levels and high lysine trimethylation levels of certain histones and histone H2A ubiquitylation (73). Histone modifications and other modifications of chromatin components are reversible and regulated by the action of enzymes termed 'writers', which are responsible for modifications such as histone acetyltransferase (HATs), histone methyltransferases, and histone ubiquitinase, and the 'erasers', which can revert those changes, including that of HDACs, histone demethylases, and histone deubiquitinases $(73,74)$.

The levels of HDAC10 expression were significantly lower in patients who had UCC lymph node metastasis compared with those without metastases. Overexpression of HDAC10 in tumor-derived cells significantly inhibited cell motility and metastasis. HDAC10 mechanistically reduces the histone acetylation of the promoter regions of the $M M P 2$ and 9 genes by suppressing the expression of these genes and preventing enzyme production, thus maintaining adherence between cells. Therefore, the reduction in HDAC10 expression enhances histone acetylation and the transcriptional activation of the MMP2 and 9 genes, in-turn promoting cell mobility, which favors invasion and metastasis of cancer cells (75).

The regulation of HPV gene expression is strongly influenced by histone modifications caused by both methylation and acetylation, but differences are observed in relation to the position of the lysine residues, which is acetylated according to the presentation form of the viral genome in the host cells. Important changes in histones, such as methylation and acetylation at positions H3 lysine 27, H3 lysine 9 and H4 lysine 20 contribute significantly to the regulation of HPV gene expression and an increase in the neoplastic progression process as the cell phenotypically progresses from a healthy state to cancerous during carcinogenesis induced by both the episomal form and the integrated form of the virus. However, trimethylation markers of $\mathrm{H} 3$ lysine 27 and trimethylation $\mathrm{H} 3$ lysine 9 decrease with neoplastic progression in carcinogenesis mediated by the integrated form of the virus $(11,76,77)$. In normal cells, the balance between HDACs and HATs means that cell death and uncontrolled proliferation are kept under control. However, in the case of UCC, which is mediated by 
HPV, the presence of the E6 and E7 viral oncoproteins upsets this balance between HDACs and HATS, resulting in uncontrolled cell growth and proliferation of cancer cells $(6,78)$.

In HPV-induced carcinogenesis, several regulatory mechanisms for the transcription of cellular and viral genes are controlled by histone modifications (11). Amongst the major cellular genes involved in this process, the TP53 and RB tumor suppressor products (p53 and pRB proteins) are the primary targets of the E6 and E7 viral oncoproteins, respectively (79). Both tumor suppressors genes target a wide range of genes and cellular mechanisms involved in multiple biological processes including cell cycle arrest, DNA repair, apoptosis, metabolism, autophagy and feedback mechanisms $(80,81)$. It has been shown that the high-risk HPV E6 protein association with the Myc transcription factor of the cell triggers the transactivation of the hTERT gene promoter by modulating histone modifications through phosphorylation, thereby resulting in increased production of the telomerase enzyme of the infected cell, which contributes to immortalization, thus increasing the risk of developing HPV-associated cancer (82).

Analysis of tumor suppressor genes, such as $R A R \beta 2$, E-cadherin and $\beta$-catenin in UCC tissues showed that their promoters are deacetylated and that lack of acetylation causes reduced or absent expression of these three genes, and this favors the development of tumor metastasis. Treatment with HDAC inhibitors, such as all-trans retinoic acid (ATRA) combined with suberoylanilide-hydroxamic acid (SAHA) increased the enrichment of acetylated histones in the promoter region of the genes. The agonists of RAR $\beta 2$ and valproic acid (VPA) significantly restored expression of RAR $\beta 2$ via epigenetic modulation. The VPA and ATRA combination showed additional antitumor effects, reactivating expression of RAR $\beta 2$, E-cadherin, P21CIP1 and P53, and reducing the expression levels of the STAT3 gene, which activates the transcription of genes that promote cell proliferation and tumor cell survival. These results suggest that treatment with HDAC inhibitors and RAR $\beta 2$ agonists may represent a novel approach for treating UCC (72).

Histone modifications are unevenly distributed throughout the HPV16 genome in both UCC cells and keratinocytes immortalized by HPV16. For example, H3K36me3 and $\mathrm{H} 3 \mathrm{~K} 9 \mathrm{Ac}$, which are the most frequent modifications in cellular genes, are more common in the early region of HPV16, whereas the H3K9me3, H4K20me3, H2BK5me1 and H4K16Ac modifications are more frequently observed in the late region. In addition, a region harboring the early polyadenylation signal of the HPV16, pAE, exhibited high levels of histone H3 acetylation. Treatment with HDAC inhibitors increased the expression of early and late HPV16 mRNAs by $2-8 x$ in cancer cells and immortalized keratinocytes, with a simultaneous increase of acetylated histone levels in both the host cell DNA and in the HPV16 genome (83).

Analysis of HDAC3 expression in specimens of normal cervical tissue, moderate (grade 2) and severe (grade 3) CIN and UCC showed that the expression of HDAC3 was significantly higher in the cancerous tissues compared with those of normal tissues, or CIN2 and CIN3. This suggests HDAC3 may serve an important role in the course of UCC carcinogenesis (84).

The E6 protein of high-risk HPVs can degrade p53, activate telomerase and stimulate the expression of several cell oncogenes (10). Evidence shows that E6 of the HPV16 physically interacts with histone $\mathrm{H} 3 \mathrm{~K} 4$ demethylase KDM5C, promoting its E6AP proteasomal degradation in an E3 ligase-dependent manner (85). CaSki cells, cancer cells positive for HPV16, exhibit lower KDM5C levels than cancer cells that are negative for HPV. It has been shown that the CaSki cells contain enhancers in super-EGFR and the c-MET oncogene, and that KTM5C overexpression reduces the effects of these super-enhancers and expression of these oncogenes. It is hypothesized that this phenomenon is due to modulation of H3K4me3 and H3K4mel dynamics, as well as decreased transcription of the super-enhancers since deletion of KDM5C or E6 of the HPV16 activates these two elements. These results suggest that epigenetic activation of the E6-mediated cell genome results in the expression of important oncogenes, such as EGFR and c-MET (85).

\section{The role of ncRNAs in HPV-induced UCC}

NcRNAs are single-stranded RNA transcripts that, in general, do not encode proteins, although certain transcripts have been shown to possess protein or peptide-coding potential. NcRNAs are divided into three classes: miRNAs, long non-coding RNAs (lncRNAs), and circular non-coding RNAs (circRNAs). These transcripts are emerging as major players in tumorigenesis, due to advances in biotechnology and high-throughput sequencing that have enabled functional studies of these transcripts, providing a novel perspective in the understanding and potential treatment of cancer (86). The ncRNAs can be transported via vesicles called exosomes released by almost all types of cells, and can act as transport vehicles for molecules, including viral proteins and genetic material, such as ncRNAs, which can affect distant receptor cells, triggering inflammatory processes (87).

Regarding UCC, the process of carcinogenesis is triggered by persistent infection with high-risk HPV and occurs through a gradual progression from precursor lesions to invasive cancer (88). Evidence obtained from studies performed on tumor tissues and tumor-derived cell lines show that the aberrant expression of ncRNAs serves critical roles in the onset and progression of the disease (89). They can affect signaling pathways, such as E6-p53, E7-pRb, PI3K-Akt, Notch and Wnt- $\beta$-catenin, amongst others. Thus, ncRNAs can serve as biomarkers or therapeutic targets, and may possess value for use in clinical practice $(90,91)$.

Tumor cells develop epigenetic mechanisms that allows them to acquire novel capabilities, such as resistance to apoptosis, increased proliferation, immune modulation, migration, survival, vascularization and invasion through the deregulation of cell signaling pathways, thereby creating advantageous conditions for cancer development (92). One of the bases of these mechanisms is the expression of miRNAs, which regulates the expression of genes at both the mRNA and protein levels, degrading target mRNA and/or silencing their translation. Several deregulated miRNA encoding genes are involved in the initiation, progression and metastasis of various types of tumors $(93,94)$.

miRNAs. The process of tumorigenesis, including cervical carcinogenesis induced by high-risk HPVs, can be influenced 
by positive or negative regulation of both cellular and viral genes mediated by miRNAs (95). The increased expression of certain miRNAs serves a critical role in the initiation and progression of UCC, since they positively regulate the proliferation, mobility and invasiveness of cancer cells, whilst inhibiting apoptosis and cell adhesion. These transcripts are involved in the inactivation of tumor suppressor genes or in the activation of cellular or HPV oncogenes, with particular activity on transcription factors involved in the expression of target genes. These miRNAs are upregulated in UCC and in cell lines derived from UCC, due to the action of viral oncoproteins (96).

In cells infected with high-risk HPVs, miRNAs regulated by tumor suppressor genes, particularly TP53 and RB, have protective functions against UCC, and act to control the cell cycle, repair to DNA damage, senescence and apoptosis of the infected cells. Thus, certain miRNAs, including miR-23b, miR-34a, miR-107, miR143 and miR-206, expression of which is increased by the tumor suppressor cellular protein p53, are downregulated in UCC, due to the degradation of this protein by the action of the viral oncoprotein E6 (97-99). On the other hand, miR-15 and miR-16, whose expression is activated by cellular protein $\mathrm{pRB}$, is also downregulated in $\mathrm{UCC}$ due to the degradation of this tumor suppressor protein by the action of the E7 viral oncoprotein $(100,101)$. The negative regulation of these miRNAs by both mechanisms contributes to tumor initiation and progression (Table I; Fig. 2).

The HPV-16 E6 oncoprotein, by degrading p53 in infected cells, can cause aberrant methylation and contribute to the development of UCC, as E6 positively regulates the DNMT1 gene. It was seen that miR-23b, which has tumor suppressor action, is silenced in cells derived from UCC due to the methylation of its promoter. miR-23b targets the $c-M E T$ oncogene, silencing the gene that encodes this transcript increases c-MET expression, which favors tumor initiation and progression (97). miR-34a and miR-206 acts as a tumor suppressor in a p53-dependent manner, repressing the expression of the BCL2 gene, leading to the induction of apoptosis and the suppression of the $c$-MET oncogene and preventing its transforming action. However, in the high-risk HPV-infected cells, the E6 protein degrades p53 and reverses the protective effects of these two miRNAs, which results in the inhibition of apoptosis of the infected cell, in addition to activating the c-MET oncogene. The positive regulation of $\mathrm{Bcl} 2$ and c-MET promotes the progression of precancerous cervical lesions to UCC (98).

The Musashi 2 RNA-binding protein encoded by the MSI-2 gene is highly expressed in UCC and presents an inverse relationship with the expression of miR-107 and miR-143. The Musashi 2 protein binds to the oncogene $c$-FOS mRNA, increasing the expression of the c-FOS protein, which is associated with increased proliferation, invasiveness of tumor cells, and lower patient survival. miR-107 and miR-143 directly target the MSI-2 gene, whose expression can be inhibited by the presence of the functional p53 protein. However, the degradation of p53 by the viral E6 protein neutralizes the tumor suppressing action of these miRNAs (99). The low expression of miR-143 is also associated with increased expression of the GOLM1 gene encoding Golgi phosphoprotein 2, and this condition results in increased proliferation, migration and invasion of tumor cells. This is due to the absence of the p53 function, which prevents the tumor suppressor action of miR-143 on GOLM1 expression (102).

Under normal conditions, miR-139-3p acts by inhibiting the expression of HPV16 oncogenes, whose products, the oncoproteins E6 and E7, target the cellular proteins p16, p21 and p53. The silencing of these viral genes by miR-139-3p maintains cell cycle arrest in the G2-M phase, inhibits proliferation and migration, and induces apoptosis of cells infected by HPV16. Increased DNA methylation of the promotor of miR-139-3p harboring the gene PDE2A was observed in HPV-16-positive tissues and cancer cell-lines (103).

miR-218 is downregulated in UCC, presenting an inverse correlation between the expression of miR-218 and expression of the DCUN1D1 gene that encodes the cancer-related DCUN1D1 protein and the SFMFBT1 gene, both with a tumorigenic role. The increased expression of SFMBT1 induced epithelial-mesenchymal transition and increased the migration and invasiveness of cancer cells, while the increased expression of DCUN1D1 increased the proliferation, migration and invasiveness of these cells, but did not induce epithelial-mesenchymal transition. The HPV16 E6 protein inhibited the expression of miR-218 in UCC, and restoration of $\mathrm{miR}-218$ reversed the effects of E6 in activation the expression of SFMBT1 and DCUN1D1 (104). In another study, it was found that downregulation of miR-218 results in overexpression of the IDOI gene, which encodes the enzyme indoleamine 2,3-dioxigenase 1, which is associated with inhibition of Caspase-3 and apoptosis. Furthermore, this enzyme activates the JAK2/STAT3 signaling pathway, which leads to increased expression of immune factors, such as TGF- $\beta$, VEGF, IL-6, PGE2 and COX-2, increasing the viability of tumor cells, which favors tumor progression (105).

The miR-15/16 family members, including miR15a, miR-15b, miR-16-1 and miR-16-2 act as tumor suppressors, promoting the arrest of the cell cycle via a pRB-dependent mechanism, which results in inhibition of the expression of cyclins A and E. These cyclins are necessary for the activation of E2F, a key transcription factor that activates the genes that promote cell cycle progression (100). The low expression of miR-15a-5p was observed in cervical cancer tumor tissues with distant metastases and in cervical cancer cell lines. Upregulation of miR-15a-5p suppressed the viability, migration and invasion of tumoral cells. The oncogene yes-associated protein 1 was confirmed to be a target of this miRNA (101). However, the E7 protein of the high-risk HPVs neutralizes the protective functions of these transcripts, preventing their expression through the degradation of cellular $\mathrm{pRB}$. In addition, E7 is also capable of directly inducing the expression of cyclins $\mathrm{A}$ and $\mathrm{E}$, thus promoting the progression of the cell cycle $(106,107)$. miR-15 and miR-16 also possess tumor suppressor functions in UCC, as they induce the silencing of the TCF3 gene that encodes a transcription factor involved in the activation of proliferation, migration and invasion of the cancerous cells in this tumor (108).

Certain miRNAs are upregulated in UCC, acting by silencing tumor suppressor genes or activating oncogenes (Table II). miR-20b is upregulated in cells derived from UCC through the action of the HPV E6 oncoprotein, whereas the tissue inhibitor of metalloproteinase 2 (TIMP-2), which is a 
Table I. Downregulated tumor suppressor miRNAs in UCC.

\begin{tabular}{|c|c|c|c|c|c|}
\hline First author, year & miRNA & Activator & Target gene & Physiolgocial function & (Refs.) \\
\hline Yeung et al, 2017 & $23 b$ & p53 & SIX1 & $\begin{array}{l}\text { Affects AKT/mTOR signaling pathway as well as progress } \\
\text { of epithelial-mesenchymal transition. }\end{array}$ & $(97)$ \\
\hline Chen et al, 2017 & $34 \mathrm{a}$ & p53 & $W N T-\beta$ & $\begin{array}{l}\text { Inhibition of the exchange of E-P cadherin, interfering in the } \\
\text { WNT- } \beta \text {-catenin pathway. }\end{array}$ & $(98)$ \\
\hline \multirow[t]{2}{*}{ Dong et al, 2017} & \multirow[t]{2}{*}{107} & \multirow[t]{2}{*}{ p53 } & MCL1 & $\begin{array}{l}\text { Suppression of MCL1 expression, affecting ATR/Chk1 } \\
\text { signaling path. }\end{array}$ & \multirow[t]{2}{*}{$(99)$} \\
\hline & & & $M S I-2$ & $\begin{array}{l}\text { Inhibition of MSI- } 2 \text { expression, which product promotes } \\
\text { cell cycle progression. }\end{array}$ & \\
\hline \multirow[t]{2}{*}{ Dong et al, 2017} & \multirow[t]{2}{*}{143} & \multirow[t]{2}{*}{ p53 } & GOLM1 & $\begin{array}{l}\text { Inhibition of GOLM1 gene expression, responsible for } \\
\text { encoding protein } 1 \text { in the Golgi membrane. }\end{array}$ & \multirow[t]{2}{*}{$(99)$} \\
\hline & & & $M S I-2$ & Inhibition of MSI-2 expression. & \\
\hline Chen et al, 2017 & 206 & p53 & G6PD & $\begin{array}{l}\text { Suppression of glucose- } 6 \text {-phosphate dehydrogenase gene } \\
\text { expression. }\end{array}$ & $(98)$ \\
\hline Ofir et al, 2011 & $15 a-5 p$ & $p R B$ & $Y A P 1$ & $\begin{array}{l}\text { Inhibits } Y A P 1 \text { oncogene expression, increases apoptosis, } \\
\text { and reduces tumor cell migration and invasion. }\end{array}$ & $(100)$ \\
\hline Ofir et al, 2011 & $16-1$ & $p R B$ & CCNE1 & $\begin{array}{l}\text { Post-transcriptionally suppression of the } C C N E 1 \text { gene } \\
\text { expression, which product promotes cell cycle progression. }\end{array}$ & $(100)$ \\
\hline Chen et al, 2017 & $34 \mathrm{a}$ & $p R B$ & $E 2 F 3$ & Repression of $B C L 2$ gene expression, inducing apoptosis. & $(98)$ \\
\hline $\begin{array}{l}\text { Sannigrahi et al, } \\
2017\end{array}$ & $139-3 p$ & - & E6 and E7 HPV & Inhibition of HPV16 E6 and $E 7$ oncogenes expression. & $(103)$ \\
\hline \multirow[t]{2}{*}{ Jiang et al, 2016} & \multirow[t]{2}{*}{218} & \multirow[t]{2}{*}{-} & SFMFBT1 & $\begin{array}{l}\text { Inhibition of } S F M F B T 1 \text { gene expression, which induces } \\
\text { epithelial-mesenchymal transition and increases migration } \\
\text { and invasion of tumor cells. }\end{array}$ & \multirow[t]{2}{*}{$(104)$} \\
\hline & & & DCUN1D1 & $\begin{array}{l}\text { Inhibition of } D C U N 1 D 1 \text { gene expression, the product of } \\
\text { which increases proliferation, migration and invasion, but } \\
\text { does not induce epithelial-mesenchymal transition. }\end{array}$ & \\
\hline
\end{tabular}

UCC, uterine cervix cancer; miRNA, microRNA; HPV, human papillomavirus.

metastasis suppressor, has been identified as a novel target of miR-20b and showed an inverse correlation with this miRNA. Overexpression of miR-20b resulted in morphological changes in the cells and induced epithelial-mesenchymal transition. The treatment of cancer cells with miR-20b inhibitors decreased the migration and invasion of these cells. TIMP-2 has been shown to be regulated in an E6-dependent manner. This suggests that miR-20b is activated by the viral protein E6, and inhibits TIMP-2 expression thus increasing the invasiveness of cancer cells (109).

The E7 protein of high-risk HPVs also serves an oncogenic role by directly activating the expression of tumor-inducing miRNAs, such as miR-21-5p, which induces angiogenesis and tumor growth in UCC, as well as increasing invasion and metastasis of tumor cells (110). The von Hippel-Lindau tumor suppressor gene (VHL) has been identified as a direct target of miR-21-5p, and VHL knockout results in abolishment of the inhibitory function of miR-21-5p, and increases proliferation and metastasis of UCC derived cells. This shows that miR-21-5p acts as a tumor promoter in UCC through negative regulation of the expression of VHL (111). In addition, miR-21-5p positively regulates the expression of TNF- $\alpha$, which promotes tumorigenesis (112). E7 also upregulates miR-27b, which inhibits the expression of the tumor suppressor gene polo-type kinase-2, resulting in increased proliferation and inhibition of apoptosis of cancer cells (113).

E7 is able to positively regulate the expression of miR-203 and miR-323, which exhibit tumor-inducing functions. miR-203 increases the expression of the TP63 gene, which encodes p63, and miR-323 increases the expression of the APPL1 gene that encodes an adapter protein, and both proteins posses tumorigenic properties (114). p63 is a transcription factor and a member of the same family as p53. Two isoforms of this protein have been identified, one with a normal transactivation domain and another, $\Delta \mathrm{Np} 63$ with a truncated transactivation domain, and thus has an opposite function to that of p53, showing carcinogenic activity (115). miR-203 and $\Delta \mathrm{Np} 63$ showed higher levels of expression in cervical tissues obtained from UCC compared with premalignant cervical lesions. This suggests that miR-203 acts as an oncogene in UCC by activating $\triangle \mathrm{Np} 63$ expression (116). miR-323 also acts as an oncogene in UCC by activating the transcription of the APPL1 gene, which encodes an adapter protein associated with tumor cell proliferation and migration (114). 


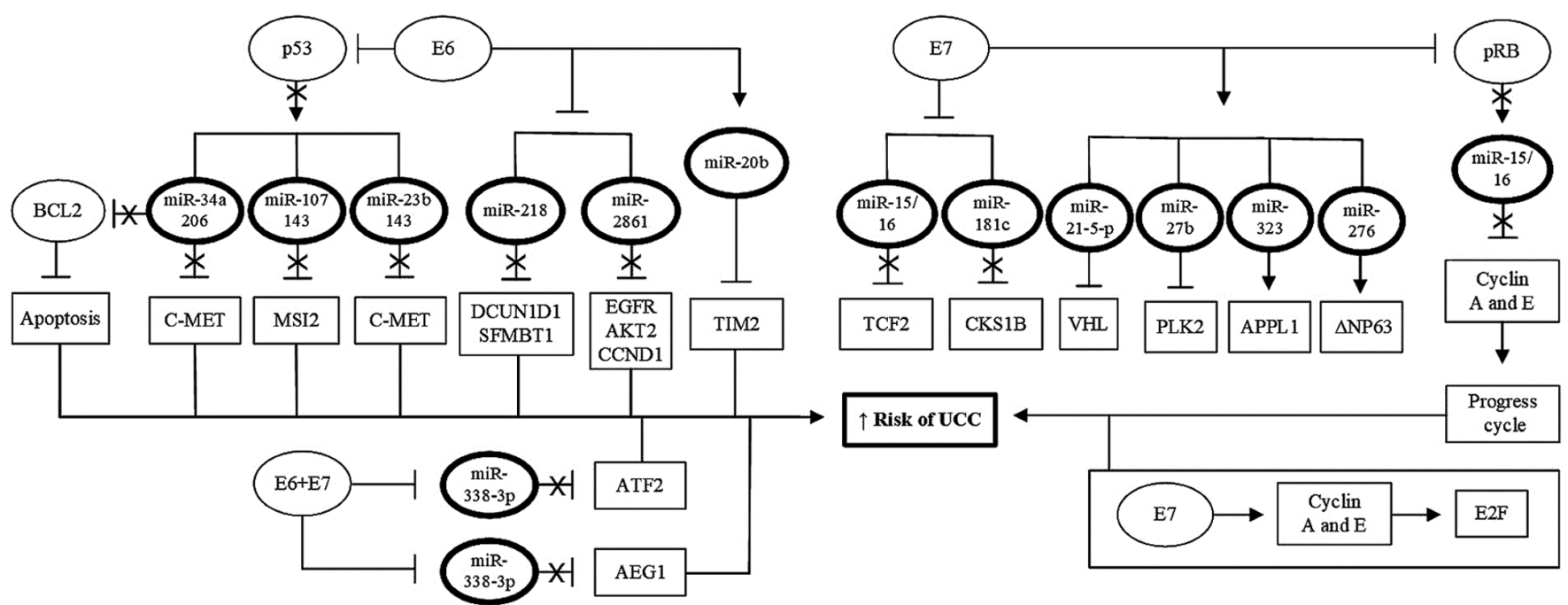

Figure 2. Role of HPV oncoproteins in regulation of miRNAs. Viral oncoproteins E6 and E7 may also serve a role in cervical carcinogenesis by regulating the expression of miRNAs that function as tumor suppressors, by inhibiting the functions of tumor suppressor cell proteins, such as p53 and pRB. By abolishing the functions of the cellular proteins p53 and pRB, viral proteins E6 and E7 prevent these two cellular proteins from activating the expression of protective miRNAs against UCC, thus preventing inhibition of the transcription of cellular oncogenes associated with tumor initiation and progression. In addition, E6 and E7, acting either alone or together, can also directly activate the expression of tumor-inducing miRNAs which increases expression of oncogenes or inhibits the expression of tumor suppressor genes. This results in increased proliferation, immortalization, progression and invasion of tumor cells. UCC, uterine cervix cancer; HPV, human papillomavirus; miRNA/miR, microRNA.

The expression levels of miR-203 and miR-323 are upregulated in cells derived from UCC and are positively correlated with the expression of the mRNA levels of oncoprotein E7 of HPV16. The positive correlation between E7 and miR-323 expression is more evident when the virus is in the episomal form, whereas for miR-203 this correlation is more evident when the virus is in its integrated form. This indicates that the HPV16 E7 oncoprotein increases the expression of miR-203 and miR-323, which contribute to HPV 16-induced carcinogenesis. On the other hand, the expression of miR-181c is downregulated in HPV-16 positive UCC only when the virus is in its episomal form, and it is negatively correlated with the expression of the $C K S 1 B$ gene, which regulates $\mathrm{G} 2 / \mathrm{M}$ transition (117). The suppression of $C K S 1 B$ promotes dysregulation of the cell cycle and prevents the repair of DNA damage, which results in the accumulation of mutations generating genomic instability and contributes to the transformation of the cell and acquisition of a malignant phenotype (118). A summary of the primary miRNAs regulated by the viral oncoproteins and their respective mechanisms of action is presented in Fig. 2.

The group of miRNAs with increased expression in cells derived from UCC are associated with a greater risk of disease initiation and progression, and are considered UCC-inducing miRNAs. Bioinformatics analysis revealed that miR-106b-5p could modulate the expression of GSK3B, VEGFA and PTK2 genes, all of which have an important role in the PI3K-Akt signaling pathway (119). In addition, miR-106b increases migration of cancer cells by inhibiting the expression of the $D A B 2$ gene, resulting in TGF- $\beta 1$-mediated induction of metastasis (120).

The expression of miR-125a-5p is upregulated in cells derived from UCC, whereas the protein expression levels of microtubule-1 affinity regulating protein kinase (MARK1) were decreased. The UCC-derived HeLa and C-33A cell lines exhibited increased migration after transfection with miR-125a-5p mimics and the migration of these cells was also increased by inhibiting the expression of the $M A R K 1$ gene. These results show that miR-125a-5p acts as a tumor inducer in UCC, targeting the MARK1 gene, expression of which is inhibited by miR-125a-5p, thus favoring the migration of tumor cells (121).

miR-135b functions by silencing the tumor suppressor gene FOXO1, which encodes a transcription factor that controls the progression of the cell cycle. This condition favors the proliferation of cancer cells (122). miR-141-3p is associated with proliferation, epithelial-mesenchymal transition, tumor growth and invasion with lymph node metastases. miR-135b functions by targeting and silencing the tumor suppressor gene FOXA2, whose product is a transcription factor that controls these cellular processes (123). miR-150-5p is upregulated in cells derived from UCC, and is negatively correlated with the expression of the gene encoding SRC kinase signaling inhibitor 1 (SRCINI). Overexpression of SRCIN1 inhibits proliferation and epithelial-mesenchymal transition of cancer cells triggered by miR-150-5p mimics, and increases apoptosis of cervical carcinoma cells. These results show that miR-150-5p promotes cell proliferation and epithelial-mesenchymal transition through silencing SRCINI (124).

miR-155-5p is upregulated UCC tissues compared with normal tissues, and is inversely correlated with the expression of the tumor suppressor TP53INP1. Transfection of miR-155-5p inhibitors decreased proliferation, migration and invasion of cancer cells in vitro, whereas miR-155-5p mimics had the opposite effect. Knockdown of TP53INP1 mimicked the effects of miR-155-5p on the activation of proliferation, migration and invasion of tumor cells, whereas overexpression of TP53INP1 reversed these effects. These results show that miR-155-5p functions as an oncogene in UCC by inhibiting the expression of the tumor suppressor TP53INPI (125).

miR-181a-5p inhibits apoptosis and increases proliferation and invasion of cancer cells by negatively regulating the 
Table II. Upregulated tumor-inducing miRNAs in the UCC.

\begin{tabular}{|c|c|c|c|c|c|}
\hline First author, year & miRNA & Activator & Target gene & Function in cells derived from the UCC & (Refs.) \\
\hline Cheng et al, 2017 & $20 \mathrm{~b}$ & E6-HPV & TIMP2 & $\begin{array}{l}\text { Induces production of matrix metalloproteinases } \\
\text { and increases migration and invasion of tumor cells. }\end{array}$ & $(109)$ \\
\hline $\begin{array}{l}\text { Kong et al, 2015; } \\
\text { Cai et al, } 2018\end{array}$ & $21-5 p$ & E7-HPV & $V H L$ & $\begin{array}{l}\text { Inactivation of VHL tumor suppressor gene, promoting } \\
\text { proliferation and metastasis of tumor cells. }\end{array}$ & $(110,111)$ \\
\hline Liu et al, 2016 & $27 b$ & E7-HPV & PLK2 & $\begin{array}{l}\text { Inhibition of polo-like kinase- } 2 \text { tumor suppressor gene, } \\
\text { increasing proliferation and inhibiting apoptosis. }\end{array}$ & $(113)$ \\
\hline $\begin{array}{l}\text { Ding et al, 2014; } \\
\text { Park et al, 2019; } \\
\text { Coimbra et al, } 2016\end{array}$ & 203 & E7-HPV & TP63 & $\begin{array}{l}\text { Activation of TP } 63 \text { expression, which encodes an } \\
\text { isoform of this protein, } \Delta \mathrm{Np} 63 \text { without the } \\
\text { transactivation domain, which exhibits tumor-inducing } \\
\text { function. }\end{array}$ & $(114-116)$ \\
\hline Ding et al, 2014 & 323 & E7-HPV & APPL1 & $\begin{array}{l}\text { Activation of APPL1 gene expression, which encodes } \\
\text { an adapter protein, both with tumorigenic properties. }\end{array}$ & $(114)$ \\
\hline Cheng et al, 2016 & $106 b$ & - & $D A B 2$ & $\begin{array}{l}\text { Inhibition of } D A B 2 \text { gene expression, increasing the } \\
\text { potential of TGF- } \beta 1 \text { to induce cancer cell metastasis. }\end{array}$ & $(120)$ \\
\hline Natalia et al, 2018 & $125 a-5 p$ & - & MARK1 & $\begin{array}{l}\text { Inhibition of } M A R K 1 \text { gene expression and } \\
\text { phosphorylation of associated proteins favoring } \\
\text { cell migration. }\end{array}$ & $(121)$ \\
\hline Xu et al, 2015 & $135 b$ & - & FOXO1 & $\begin{array}{l}\text { Silencing of } \mathrm{FOXO1} \text { gene, which encodes a transcription } \\
\text { factor that controls the progression of the cell cycle. }\end{array}$ & $(122)$ \\
\hline Li et al, 2018 & $141-3 p$ & - & FOXA2 & $\begin{array}{l}\text { Silencing of the FOXA2 gene, which controls } \\
\text { proliferation, epithelial-mesenchymal transition, tumor } \\
\text { growth, and metastatic invasion. }\end{array}$ & (123) \\
\hline Zhu and Han 2019 & $150-5 p$ & - & SRCIN1 & $\begin{array}{l}\text { Promotes cell proliferation and epithelial-mesenchymal } \\
\text { transition by silencing } S R C I N 1 \text {, an inhibitor of these } \\
\text { processes. }\end{array}$ & (124) \\
\hline Li et al, 2019 & $155-5 p$ & - & TP53INP1 & $\begin{array}{l}\text { Inhibition of TP53INP1, a tumor suppressor gene, which } \\
\text { controls proliferation, migration and invasion of tumor } \\
\text { cells. }\end{array}$ & $(125)$ \\
\hline Yang et al, 2018 & $181 a-5 p$ & - & INPP5A & $\begin{array}{l}\text { Inhibition of apoptosis and increases proliferation and } \\
\text { invasion of cancer cells by silencing the INPP } 5 A \text { gene } \\
\text { that controls these processes. }\end{array}$ & $(126)$ \\
\hline $\begin{array}{l}\text { Farzanehpour } \\
\text { et al, } 2019\end{array}$ & 192 & - & $\mathrm{CDH} 1$ & $\begin{array}{l}\text { Increases expression of } \mathrm{ZEB} 1 \text { and } \mathrm{ZEB} 2 \text {, which } \\
\text { inhibits the expression of } \mathrm{CDH} 1 \text { gene, the gene } \\
\text { encoding E-cadherin. }\end{array}$ & $(127)$ \\
\hline Hou et al, 2014 & $196 a$ & - & $\begin{array}{l}\text { FOXO1 and } \\
\text { p27Kip1 }\end{array}$ & $\begin{array}{l}\text { Silencing of } F O X O 1 \text { and p } 27 \mathrm{Kip} 1 \text { genes, the products } \\
\text { of which act as inhibitors of the PI3K/Akt pathway, thus } \\
\text { increasing cell proliferation. }\end{array}$ & (128) \\
\hline Chu et al, 2014 & $590-5 p$ & - & CHL1 & $\begin{array}{l}\text { Silencing of the } C H L 1 \text { gene reducing the production of a } \\
\text { molecule, increasing mobility, and invasion of tumor } \\
\text { cells. }\end{array}$ & $(131)$ \\
\hline
\end{tabular}

UCC, uterine cervix cancer; miRNA, microRNA; HPV, human papillomavirus.

INPP5A gene that encodes the enzyme inositol polyphosphate-5-phosphatase $\mathrm{A}$, which is involved in the activation of several cellular processes (126). High levels of miR-192 in the serum and tissues of patients with HPV positive UCC HPV has been suggested as a possible diagnostic biomarker. miR-192 functions by binding to the inhibitors of transcription factors of E-cadherin, ZEB1 and ZEB2, promoting the activation of these transcription factors, thus reducing the expression of the $C D H 1$ gene, which encodes E-cadherin. The reduction in E-cadherin expression decreases the adhesion between cells, favoring cancer cell mobility and the formation of metastases (127). 


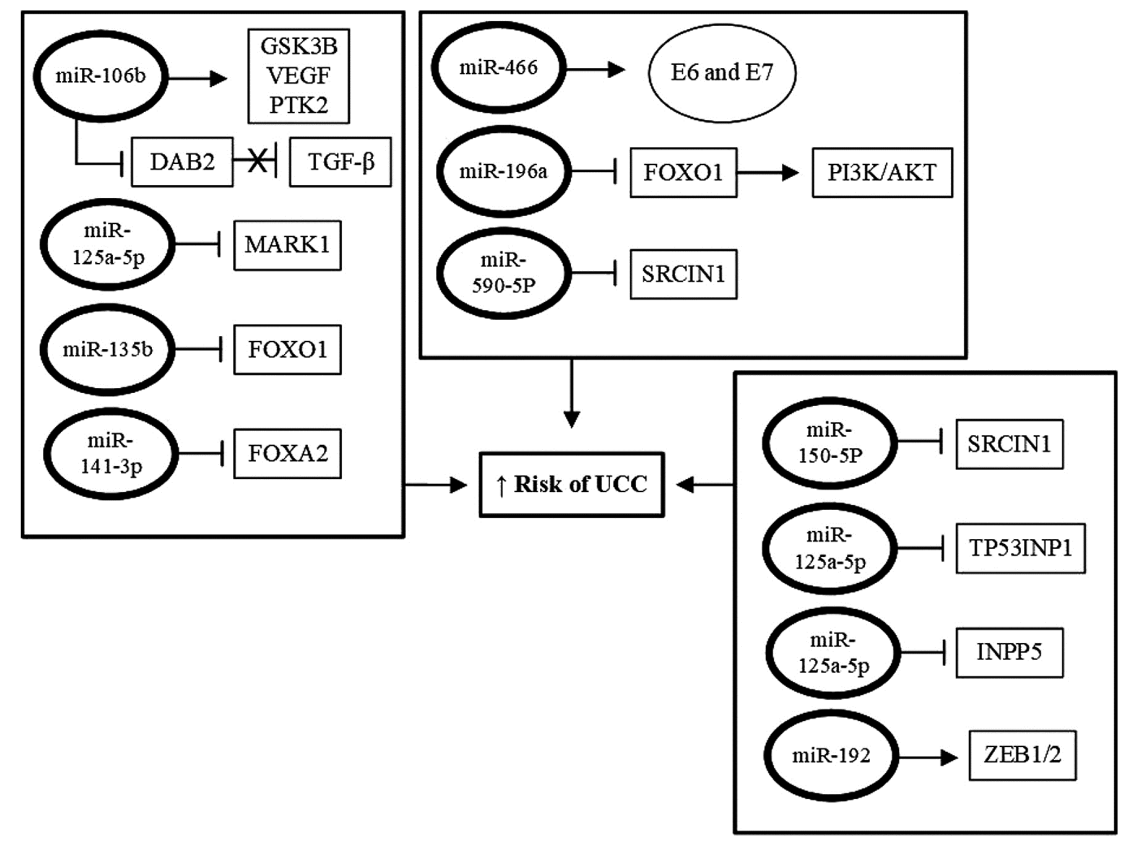

Figure 3. Role of miRNAs in induction of cervical carcinogenesis. Certain miRNAs possess tumor-promoting functions in UCC by increasing the expression of both HPV and host cell oncogenes, or inhibiting the expression of tumor suppressor genes. In cells derived from UCC, expression of these miRNAs is upregulated, together with the viral and cellular oncogenes controlled by these transcripts, whereas the target tumor suppressor genes of these miRNAs is downregulated in these cells. This positive regulation of viral or cellular oncogenes, and the inhibition of the expression of tumor suppressor genes, results in increased proliferation, immortalization, progression and invasion of tumor cells. UCC, uterine cervix cancer; HPV, human papillomavirus; miRNA/miR, microRNA.

Expression levels of miR-196a are significantly increased in tissues and cell lines derived from UCC compared with the corresponding normal tissue. The positive regulation of miR-196a is associated with advanced stage tumors and low overall survival rates of patients. Positive regulation of miR-196a increased G1/S phase transition and the proliferative capacity of cancer cells, whereas forced suppression of miR-196a had the opposite effect. This transcript has been shown to act as a tumor inducer in UCC by inhibiting the expression of the FOXO1 and p27Kip1 genes, whose products inhibit the PI3K/Akt signaling pathway. Furthermore, the negative regulation of these transcription factors by miR-196a leads to the activation of this pathway, increasing cell proliferation and favoring the development of the tumor (128). However, it was shown that the gene encoding miR-196a-1 exhibits higher levels of methylation in cells derived from UCC, compared with premalignant lesions. Treatment with a demethylating agent reactivated the expression of miR-196a in $\mathrm{SiHa}, \mathrm{HeLa}$ and CaSki cells, all of which are derived from UCC. In addition, expression levels of miR-196a-1 were negatively correlated with methylation levels in clinical samples. It has been shown that miR-196a-1 targets the AT-Hook 1 gene of the High Mobility Group, which encodes a protein capable of modulating transcription by altering the chromatin architecture. This suggests that the silencing of miR-196a-1 gene by methylation from its promoter increases $H M G B 1$ expression, and may contribute to carcinogenesis in UCC (129).

miR-466 acts as an oncogene, possibly serving a role in increasing the expression of viral oncogenes. Bioinformatics analysis showed that this transcript was homologous to the LCR of the genomes of HPVs 16 and 18. High levels of
miR-466 expression are strongly correlated with the progression and invasive capacity of cancer cells, and is associated with lymph node metastases and reduced patient survival (130). miR-590-5p also acts to promote cervical carcinogenesis by targeting the CHL1 gene, which encodes an adhesion molecule. Negative regulation of $\mathrm{CHLl}$ by miR-590-5p results in an increase in the proliferative and migratory capacity of cancer cells, and inhibits differentiation and apoptosis of these cells (131). A summary of the primary miRNAs with tumor-inducing functions and their likely mechanisms of action are presented in Fig. 3 .

The expression of certain miRNAs are reduced in UCC cells, suggesting that these transcripts under normal conditions exert protective functions against the tumor and act by negatively regulating the expression of oncogenes or by increasing the expression of tumor-suppressor genes. However, this function can be abolished by mechanisms triggered by viral oncoproteins (132). MiRNAs with tumor-suppressive function target cellular genes, particularly transcription factors involved in regulation of the cell cycle, proliferation and invasion of cancer cells, which are downregulated in UCC-derived cells $(133,134)$. A summary of the primary miRNAs that possess tumor-suppressive functions in cervical carcinogenesis is presented in Fig. 4.

Studies have shown that miR-29a is downregulated in UCC, resulting in upregulated expression of the oncogene ITGBI, whose product, integrin $\beta 1$, promotes proliferation and migration of tumor cells, causing metastasis to lymph nodes (135). This indicates that miR-29a exerts a tumor suppressor function by directly inhibiting the expression of $I T G B 1$ and therefore, in its absence, tumor progression occurs (94). miR-145 is negatively regulated in UCC, and is inversely correlated with 


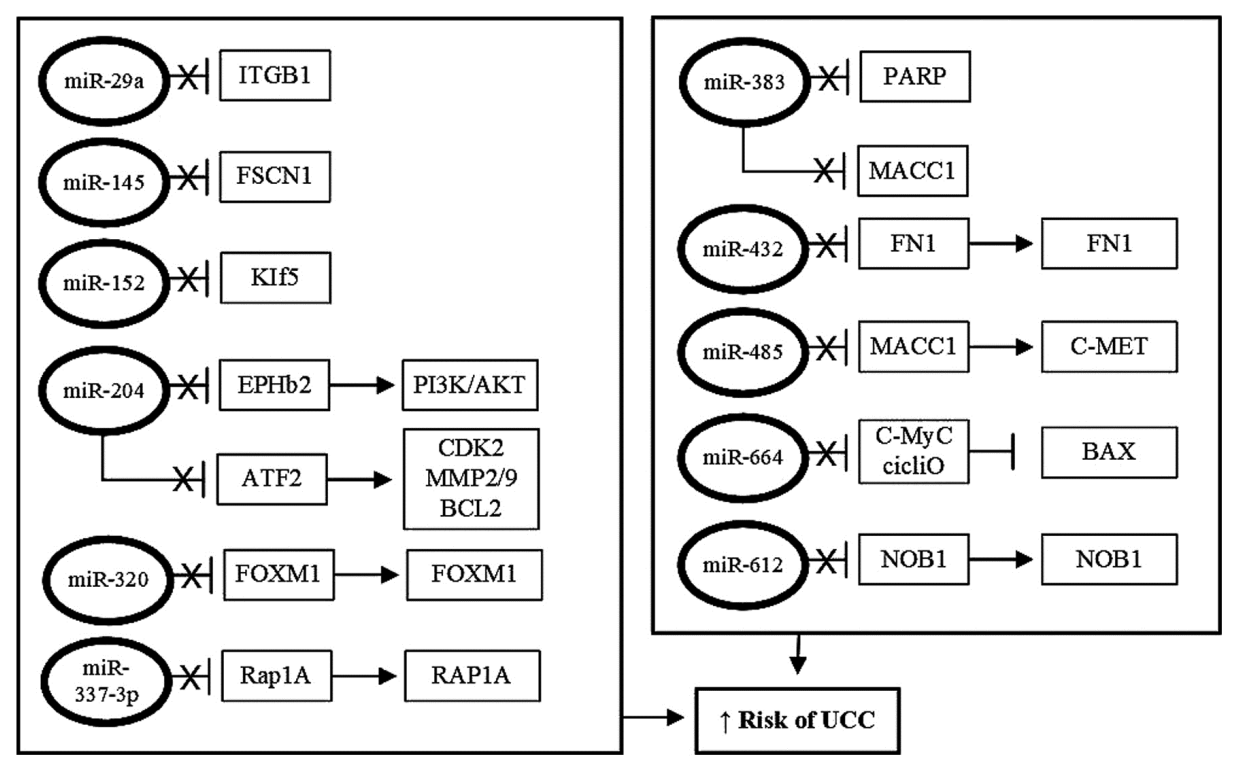

Figure 4. Protective roles of miRNAs against cervical carcinogenesis. Tumor suppressor miRNAs, under physiological conditions, exhibit protective functions against the development to UCC, acting as activators of the expression of tumor suppressor genes, whose products act by suppressing the expression of oncogenes. However, in UCC-derived cells, the expression tumor suppressing miRNAs is downregulated, via different mechanisms, and this effectively abrogates their suppressive functions on the expression of oncogenes involved in proliferation, immortalization and progression of UCC. UCC, uterine cervix cancer; $\mathrm{miRNA} / \mathrm{miR}$, microRNA.

the expression of the FSCNI gene, which itself is upregulated in tumor tissues when compared with normal tissues. Overexpression of miR-145 significantly reduced the proliferation of HeLa cells and reduced the expression of FSCN1. This shows that, under physiological conditions, miR-145 functions as a tumor suppressor by inhibiting the expression of the FSCN1 gene (136).

Reduced expression of miR-204 is also associated with progression and metastasis to lymph nodes, as well as a low survival rate in patients with UCC. Overexpression of miR-204 significantly suppressed the proliferation, migration and invasion of cancer cells and promotes cell cycle arrest in the G0/G1. This is due to the interaction of miR-204 with the Ephrin type B2 receptor (EphB2). Thus, under normal conditions, miR-204 inhibits EphB2 to inhibit the PI3K/AKT signaling pathway (137). Low levels of miR-204 expression are also correlated with overexpression of the transcription factor 12 , which results in increased expression of $C D K 2$, cyclin $\mathrm{E}$, $M M P 2, M M P 9$ and $B C L 2$, and reduction of expression of $B A X$, increasing cell proliferation, migration and inhibiting apoptosis, ultimately favoring tumor progression (138). Conversely, reducing the levels of miR-204 in UCC results in increased expression of $A T F 2$, which, in-turn, increases the expression of $B C L 2$ and $L C 3 I / I I$, inhibiting apoptosis and increasing proliferation and autophagy of cancer cells (139). This indicates that under physiological conditions, miR-204 negatively regulates $A T F 2$ expression to inhibit proliferation, migration and invasion of cervical cancer cells, and induces apoptosis of these cells (139). miR-152 is downregulated in UCC, and is negatively correlated with the expression of Krüppel-like factor-5 (KLF5), expression of which is increased in UCC. Thus, in the absence of the suppressor function of miR-152 on the KLF5 gene, KLF5 protein expression is increased; KLF5 functions as a transcription factor involved in cell proliferation (133).
miR-320 is downregulated in UCC cells, and FOXM1 is upregulated. The low expression of miR-320 is associated with increased viability, migration and invasion of cancer cells. It has been shown that overexpression of miR-320 suppresses FOXM1 expression and reduces the viability, migration and invasion of tumor cells. These results show that, under physiological conditions, miR-320 functions as a tumor suppressor by inhibiting FOXM1 expression (141). The inhibition of miR-320a results in increased proliferation, migration and invasion of cells derived from UCC. This is due to the absence of its suppressive function on FOXM1, which encodes a transcription factor involved in tumor promotion (141). miR-337-3p also acts as a tumor suppressor in UCC, inhibiting the expression of the RaplA oncogene. Furthermore, reducing the expression of this transcript results in the overexpression of Rap1A, leading to a notable increase in Rap1A protein expression, which inhibits apoptosis and increases proliferation, migration and invasion of cancer cells (142).

The expression of miR-338-3p is substantially reduced in cells derived from UCC, whereas expression of the MACC1 gene is upregulated. Upregulated expression of $M A C C 1$ is associated with advanced stage UCC and lymph node metastasis, deep invasion and shorter overall patient survival. The protein encoded by $M A C C 1$ is a growth factor that acts on the MAPK signaling pathway, which is related to increased cell proliferation and epithelial-mesenchymal transition. This shows that miR-338-3p targets the MACC1 gene, downregulating its expression to inhibit cell proliferation and epithelial-mesenchymal transition. However, the reduction in miR-338-3p expression caused by the action of viral oncoproteins, results in the opposite effect (143). Another tumor suppressor mechanism mediated by miR-338-3p involves the suppression of the ATF2 gene, which is neutralized by the action of oncoproteins produced by high-risk HPVs. This results is an increase in the expression of ATF2 protein, which 
functions as an activator of the mTOR signaling pathway, increasing the proliferation and autophagy of infected cells. Restoration of miR-338 expression inhibited the proliferation of UCC-derived SiHa and HeLa cells, which are positive for HPV16 and HPV18, respectively. In addition, the reduction of miR-338 expression decreased the expression of phospho-(p-) mTOR and p-p70S6. This suggests that under physiological conditions, miR-338 inhibits proliferation and autophagy, by inhibiting the mTOR pathway, through negative regulation of ATF2 gene expression. However, this function is reversed by the action of viral oncoproteins (144).

The expression levels of miR-375 are reduced in UCC-derived cells, resulting in increased proliferation, migration and invasion of the cancer cells, inducing angiogenesis, and inhibiting apoptosis in vitro. Overexpression of miR-375 reversed these functions, resulting in the opposite effects. Astrocyte gene-1 (AEG-1) has been identified as a target of miR-375. The oncoproteins E6 and E7 of HPVs 16 and 18 downregulate miR-375 expression, resulting in increased expression of the $A E G-1$ oncogene, contributing to the initiation and progression of UCC (145). The gene encoding miR-375 showed higher levels of methylation in UCC compared with premalignant lesions. In addition, treatment with a demethylating agent increased the expression of miR-375 in SiHa and HeLa cells. Interestingly, the expression levels of this transcript were negatively correlated with the levels of methylation in clinical samples. It has been observed that miR-375 targets the Replication Factor C Subunit 3 gene, whose product is part of a transcriptional complex. This indicates that silencing by methylation of the miR-375 encoder gene promoter may facilitate the process of carcinogenesis in UCC (129).

miR-381-3p is negatively regulated, whereas the keratinocyte growth factor gene (FGF7) is upregulated in cells derived from UCC, showing an inverse correlation between the expression of miR-381-3p and FGF7. This shows that under physiological conditions, miR-381-3p can upregulate FGF7 expression, inhibiting the proliferation and metastasis of cancer cells (146). The levels of miR-383 expression are significantly lower in tissues derived from UCC compared with tissues from precancerous lesions, and there was an inverse correlation between miR-383 expression levels and that of PI3K, AKT, mTOR, PARP2 and p70S6K. Cell viability, migration and invasion were reduced in cells transfected with miR-383 mimics following knockdown of the PARP2 gene, whereas treatment with the miR-383 inhibitor increased these functions. These results suggest that, under physiological conditions, miR-383 acts as a tumor suppressor, negatively regulating the expression of $P A R P 2$ and inhibiting the PI3K-AKT-mTOR signaling pathway. Thus, in the absence of miR-383, expression of PARP2 is increased, which activates the PI3K-AKT-mTOR signaling pathway, leading to the initiation and progression of UCC (147).

miR-432 is downregulated in UCC cells, and is inversely correlated with the expression of the gene encoding fibronectin 1 (FN1). This suggests that miR-432 possesses tumor suppressive activity via inhibition of FN1 gene expression. Inhibition of miR-432 expression leads to overexpression of the fibronectin-1 protein, which induces cancer cell proliferation and invasion (134). A similar outcome is observed with miR-485, expression of which is also reduced in patients with
UCC. Downregulation of this miRNA was associated with advanced stage of the disease and lymph node metastasis. It was also found that miR-485 may exert its tumor suppressive function in cervical cancer by directly targeting MACC1 and inhibiting the Met/AKT signaling pathway (148). Conversely, downregulation of miR-664 in UCC resulted in increased expression of the c-Myc oncogene and the cyclin D gene, in-turn resulting in reduced expression of $B A X$ and active Caspase-3. This results in inhibition of apoptosis and increased cell proliferation and tumor growth (149).

The expression of miR-2861 was significantly reduced in 293T and HaCaT cells expressing the E6 protein of HPV16, compared with the control cells. miR-2861 was also shown to be downregulated in UCC cells, and its downregulation was negatively correlated with tumor stage and lymph node metastases. Overexpression of miR-2861 inhibited the proliferation and invasion of cancer cells and increased apoptosis. It was shown that the EGFR, AKT2 and CCND1 genes were all direct targets of miR-2861, and restoring the functions of these genes neutralized the suppressive effects of miR-2861. This suggests that, under physiological conditions, miR-2861 is a tumor suppressor that acts by inhibiting the transcription of $E G F R$, $A K T 2$ and/or CCND1 to regulate cell proliferation and migration. The knockdown of the miR-2861 encoding gene mediated by the E6 protein of HPV16 results in increased transcription of EGFR, $A K T 2$ and/or $C C N D 1$, thus contributing to initiation and progression of UCC (150).

miR-612 has been shown to be associated with the progression of other types of tumors; however, the expression of miR-612 was downregulated in UCC tissues and cells, and this reduced expression was associated with greater disease severity and lymph node metastasis. Overexpression of miR-612 significantly reduced the proliferation, migration and invasion of cancer cells in vitro and delayed tumor growth in vivo. miR-612 was shown to target the NOB1 gene, which encodes an RNA-binding protein; there was a negative correlation between miR-612 expression and NOB1 protein expression in UCC samples. Overexpression of $N O B 1$ partially reversed the inhibitory effects of miR-612 on tumor cells, suggesting that under physiological conditions, miR-612 acts as a tumor suppressor in UCC, by inhibiting the expression of the NOB1 gene (151).

LncRNAs. LncRNAs can modulate the progression of tumors (Fig. 5). The role of IncRNA-ANRIL was analyzed in cell lines derived from UCC, where it was shown to be positively regulated with UCC progression. Knockdown of ANRIL reduced proliferation and invasion, in addition to inducing apoptosis of cervical cancer cells. Bioinformatics analysis showed that miR-186 was a direct target of ANRIL, and ANRIL binds to miR-186 to abrogate its tumor suppressor function. Expression of miR-186 was reduced in cell lines derived from UCC and its expression was negatively correlated with the expression of ANRIL. This shows that lncRNA-ANRIL promotes UCC by sponging miR-186, to prevent its tumor suppressor action (152). A similar mechanism was observed with lncRNA-MALAT1 in relation to miR-375 (153).

It has been shown that lncRNA DDN and PRKAG1 RNA antisense 1 (DDN-AS1) are upregulated in UCC tissues and cell lines, and it is positively associated with a poor prognosis 


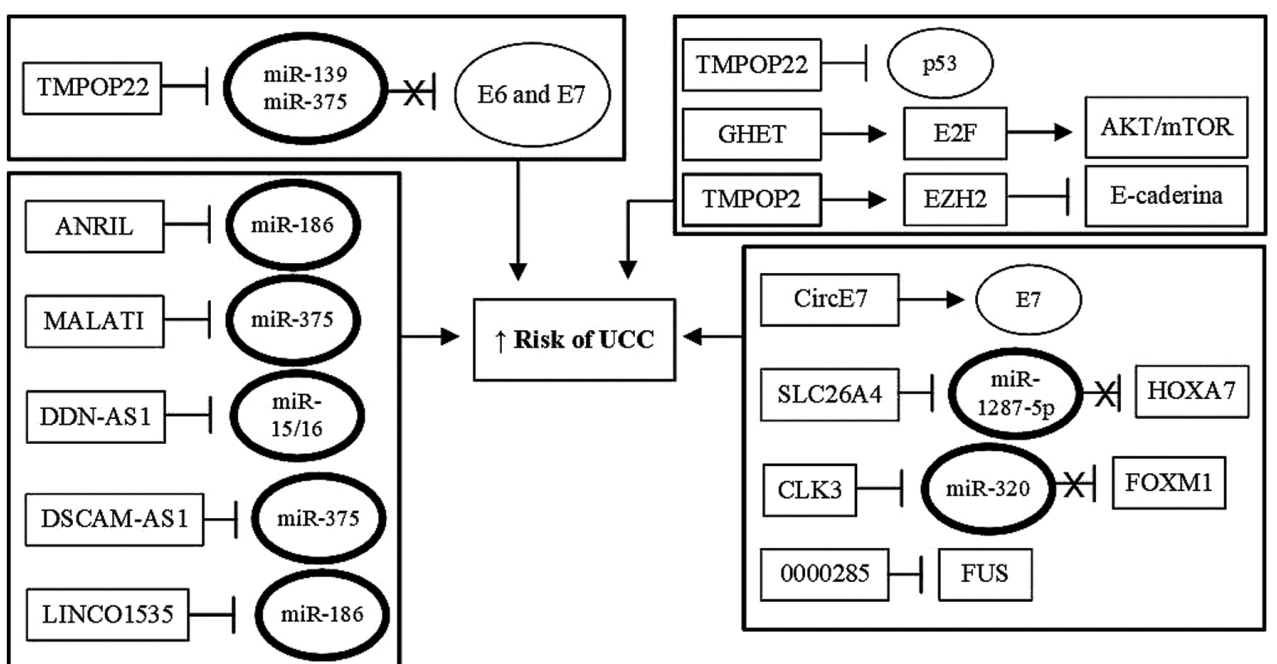

Figure 5. Role of lncRNAs and circRNAs in cervical carcinogenesis. Certain lncRNAs functions as tumor promoters in UCC, serving as a sponge of tumor suppressing miRNAs, abrogating their functions as inhibitors of the expression oncogenes of both HPV and host cells. They may also act by directly inhibiting the function of the p53 protein. Others lncRNAs act by increasing the expression of cell oncogenes. CircRNAs function as tumor promoters through different mechanisms. The circRNA CIRCe7 encodes a functional E protein of HPV, which possesses carcinogenic activity. Other circRNAs activate the expression of cellular oncogenes. Still other circRNAs function as tumor promoters, serving as a sponge of tumor suppressor miRNAs, abrogating their functions. This increases cell proliferation leading to immortalization, progression to UCC and invasion of tumor cells. lncRNA, long non-coding RNA; circRNA, circular non-coding; UCC, uterine cervix cancer.

in UCC patients. Knockdown of DDN-AS1 suppressed UCC progression by efficiently inhibiting the proliferation, migration and invasion of cancer cells. It was shown that the increase in DDN-AS1 expression was mediated by activation of the transcription factor TCF3. In addition, DDN-AS1 increased TCF3 expression by competitively binding to miR-15a and miR-16, generating a positive feedback loop in which DDN-AS1 inhibits the suppressor function of miR-15a/16 over TCF3, which in-turn activates the expression of DDN-AS1, increasing proliferation, migration and invasion of tumor cells in UCC (109).

LncRNA-DSCAM-AS1 is associated with an increased capacity for proliferation, migration and invasion of cancer cells in UCC. It was found that DSCAM-AS1 physically binds to $\mathrm{miR}-877-5 \mathrm{p}$, preventing its tumor suppressing action in which it targets the ATXN7L3 gene that encodes the histone acetylation protein complex and activates transcription by chromatin remodeling. Knockdown of DSCAM-AS1 or overexpression of miR-877-5p inhibits UCC progression. This suggests that IncRNA-DSCAM-AS1 acts by inhibiting the tumor suppressive function of miR-877-5p, interfering with a miR-877-5p/ATXN7L3 axis to promote tumor progression (1).

It has been shown that IncRNA-LINC01535 binds to miR-214, neutralizing its tumor suppressor activity, preventing the repression of the miR-214 target, the EZH2 gene, thus resulting in increased expression of the EZH2 protein. This protein was also found to directly repress miR-214 expression. Thus, by positively regulating EZH2, LINC01535 further represses miR-214 expression. The enhanced expression of LINC01535 promotes the growth, migration and invasion of cancer cells in vitro and in vivo. Knockdown of LINC01535 results in overexpression of $\mathrm{miR}-214$, thus regulating a miR-214/EZH2 axis. Knockdown of EZH2 abrogates the effects LINC01535 in UCC. Clinically, increased expression of LINC01535 is correlated with advanced tumor stage and a poor prognosis (154).
LncRNA-TMPOP2 is overexpressed in cancer cells derived from UCC and inhibits the expression of E-cadherin by recruiting the transcription repressor $E Z H 2$, the promoter of the E-cadherin gene (155). High-risk HPVs have been shown to induce degradation of the tumor suppressor p53, preventing this protein from binding to the promoter of TMPOP2 to inhibit its transcription. In addition, it was demonstrated that overexpression of TMPOP2 resulted in sequestration of tumor suppressor miRNAs, such as miR-139 and miR-375, which target the mRNAs of E6 and E7, increasing the expression of these viral proteins. Knockdown of TMPOP2 reduced the expression of positive regulatory genes of cell cycle progression, and induced arrest of the cycle, and also inhibited the proliferation of HeLa cells. This suggests that inhibition of the function of miR-139 and miR-375 by lncRNA-TMPOP2 increased the expression and transforming activity of E6 and E7 proteins (156).

The expression of IncRNA-CRNDE was increased in tissues obtained from UCC and in several tumor-derived cell lines. Knockdown of CRNDE significantly reduced the proliferation of cancer cells, whereas overexpression of this transcript significantly promoted the growth of cancer cells. CRNDE has been found to bind to the p53 upregulated modulator of apoptosis (PUMA), and PUMA is necessary for the CRNDE-mediated increase in cancer cell proliferation. Thus, it was proposed that IncRNA-CRNDE in combination with PUMA could be used for clinical diagnosis, both as a prognostic factor for UCC and as a potential therapeutic target in UCC (133).

A recent study showed that lncRNA-GHET1 is upregulated in UCC cell lines. Loss of function analysis demonstrated that the silencing of GHET1 inhibited proliferation, migration and epithelial-mesenchymal transition of these cells, as well as inhibiting the AKT/mTOR and $\mathrm{Wnt} / \beta$-catenin pathways. Conversely, the activation of these two pathways reversed the 
inhibitory effect of knockdown of GHET1 on growth, migration and epithelial-mesenchymal transition in the UCC cell lines. It was also shown that GHET1 stabilizes E2F6 mRNA, interacting with IGF2BP2, to activate the AKT/mTOR and Wnt/ $\beta$-catenin pathways. As knockdown of GHET1 resulted in the inactivation of two signaling pathways, both of which are important in cervical carcinogenesis, and inhibited the progression of UCC, GHET1 may be a promising therapeutic target for management of UCC (91).

CircRNAs. CircRNAs are a class of single-stranded RNA molecules that possess a covalently closed loop structure. They are produced by back-splicing of mRNA precursors or by jumping in the mRNAs of the genes. They are widely expressed in eukaryotes and act as critical regulators in several types of tumors. CircRNAs recruit and reprogram the primary components of the tumor microenvironment, regulating signaling pathways, modulating the immune response and affecting tumorigenesis, angiogenesis, tumor progression and metastasis (157). Their high stability, abundance and evolutionary conservation suggest a diverse set of properties with important implications for cellular functions. These transcripts can act as efficient sponges of miRNAs and proteins, and serve critical roles in the modulation of transcription. In addition, numerous circRNAs are aberrantly expressed in pathological conditions, and can be associated with initiation or progression of cancer (158).

It has been shown that oncogenic HPVs are also capable of generating circRNAs, as described in the CaSki cell line, which is derived from cervical carcinoma and is transformed by HPV 16. CircE7 is derived from the viral oncogene $E 7$ and is found primarily in the cytoplasm, where it is associated with polysomes, and it is translated into the viral oncoprotein E7. Silencing the viral gene $E 7$ or the encoding circE7 resulted in inhibition of cancer cell proliferation in vitro. CircE7 has only been detected in its episomal form in cancer cells containing HPV DNA. These results suggest that the circRNAs produced by HPV encode biologically functional proteins and they are associated with viral-mediated transformation of cells (159).

High levels of circCLK3 were found in UCC tissues and were strongly associated with advanced stage UCC and stromal invasion of the tumor. It was shown that circCLK3 functioned as a sponge to absorb miR-320a, preventing its tumor suppressor function, which under normal conditions would act by suppressing the expression of the FOXM1 gene, which encodes the FOXM1 transcription factor and is associated with disease progression (141).

CircSLC26A4 was found to be positively regulated in tissue and cell lines derived from UCC, and this high expression was associated with low patient survival. Loss of function experiments showed that the knockdown of circSLC26A4 resulted in inhibition of proliferation and invasion of cancer cells, as well as of tumor growth both in vitro and in vivo. It was found that circSLC26A4 acts as a sponge for miR-1287-5p, which, in-turn, targets the HOXA7 mRNA that encodes the homeobox-7 transcription factor (Hox-A7). It was found that the RNA-binding protein interacts with the QKI response elements in the introns of the SLC26A4 gene, to promote the biogenesis of circSLC26A4. This suggests that circSLC26A4 facilitates UCC progression, preventing the suppressive action of miR-1287-5p on the HOXA7 gene, increasing the expression of the transcription factor Hox-A7 (160).

The expression levels of circRNA_0000285 were shown to be significantly higher in UCC samples compared with the corresponding normal tissues. A positive correlation was identified between the expression of this transcript and the expression of FUS, a protein coding gene that binds to RNA, and possesses high transcriptional activity. The proliferative and migratory capacity of UCC-derived cells was notably reduced after silencing of the gene encoding circRNA_0000285. In addition, the knockdown of this gene resulted in strong inhibition of metastasis of UCC cells in nude mice. This indicates that circRNA_0000285 increases the proliferation and metastasis of cancer cells in UCC via the positive regulation of FUS (161).

Finally, a study was performed using RNA sequencing data and non-coding RNAs in cells derived from UCC, which included 102 lncRNAs, 15 miRNAs, 15 mRNAs and 522 pairs of interactions in a competing endogenous (ce)RNA network. The analysis revealed that the following genes were enriched in the network: Alcohol dehydrogenase 7 ( $A D H 7)$, a member of the vestigial family 3 ; and cytochrome P450, family 26 , subfamily B, polypeptide 1 , which is involved in the metabolic process of retinoic acid and in the retinol metabolism pathway. The ADH7 gene was regulated by miR-3065, which interacted with LINC01133 in the ceRNA network, suggesting that these transcripts may serve an important role in UCC progression (162). A summary of the role of circRNAs in cervical carcinogenesis is presented in Fig. 5.

\section{Conclusions}

Numerous clinical, epidemiological and molecular studies have shown that persistent infection with high-risk HPV genotypes is an indispensable, but not sufficient, prerequisite for the development of UCC. This suggests that the cervical carcinogenesis process induced by HPV depends on other associated risk factors, possibly generated by stressful environmental conditions, in addition to other factors the cells may experience, creating conditions favorable for malignant transformation. Therefore, for the development of cervical carcinogenesis, additional genetic and epigenetic alterations are necessary as a trigger for its initiation. These events act together through a complex process, involving multiple factors, going through several phases in the development of UCC. Such conditions disrupt cellular homeostasis and contribute to generating genomic instability, which favors the accumulation of mutations and increases the frequency of epigenetic changes. Thus, these conditions affect the functions of regulatory cell genes, which can result in activation of oncogenes or inactivation of tumor suppressor genes by silencing the gene or inactivating the function of their products.

These same changes can also occur in the viral genome, particularly affecting the expression patterns of viral oncogenes. It has been widely demonstrated that several types of epigenetic changes can affect the expression of cellular and HPV genes, participating in some manner in the process of carcinogenesis, and contributing to the initiation and progression of UCC. Thus, recent advances in cancer biology have shown that other factors, in addition to genetic mutations, may 
be implicated in the development of the disease. Epigenetic changes caused by aberrant methylation and chromatin remodeling, due to histone modifications, both in the cellular and viral DNA, serve an increasingly relevant role in cervical carcinogenesis. In addition, the participation of non-coding RNAs, such as miRNAs, lncRNAs and circRNAs, has drastically increased the complexity of our understanding of the molecular biology of cancer, whilst also providing numerous novel potential druggable targets, particularly in UCC. Therefore, these transcripts are the subject of numerous studies, aiming to discover their value as biomarkers of diagnosis and prognosis of the disease, as well as their therapeutic value for the treatment of UCC.

\section{Acknowledgements}

Not applicable.

\section{Funding}

This study was funded in part by the Coordenação de Aperfeiçoamento de Pessoal de Nível Superior-Brasil (CAPES) (grant no. 001).

\section{Availability of data and materials}

Not applicable.

\section{Authors' contributions}

MLRDS and JVF were involved in the conception of the study, literature review and drafting the manuscript. BHDRDA and VDDA were involved in drafting the manuscript. TAADMF, RNDOC, DCFL and JMGDA were involved in revising the manuscript critically for important intellectual content. FLB, VSA and JCVDA were involved in the literature review. All authors read and approved the final manuscript.

\section{Ethics approval and consent to participate}

Not applicable.

\section{Patient consent for publication}

Not applicable.

\section{Competing interests}

The authors declare that they have no competing interests.

\section{References}

1. Liang J, Zhang S, Wang W, Xu Y, Kawuli A, Lu J and Xiu X Long non-coding RNA DSCAM-AS1 contributes to the tumorigenesis of cervical cancer by targeting miR-877-5p/ATXN7L3 axis. Biosci Rep 40: BSR20192061, 2020.

2. Ferlay J, Soerjomataram I, Dikshit R, Eser S, Mathers C, Rebelo M, Parkin DM, Forman D and Bray F: Cancer incidence and mortality worldwide: Sources, methods and major patterns in GLOBOCAN 2012. Int J Cancer 136: E359-E386, 2015.

3. Torre LA, Bray F, Siegel RL, Ferlay J, Lortet-Tieulent J and Jemal A: Global cancer statistics, 2012. CA Cancer J Clin 65: $87-108,2015$
4. INCA: Estimativa 2018: Incidência de câncer no Brasil/Instituto Nacional de Câncer Jose Alencar Gomes da Silva. Coordenação de Prevenção e Vigilância, Rio de Janeiro, 2017.

5. Chen L, Qiu X, Zhang N, Wang Y, Wang M, Li D, Wang L and Du Y: APOBEC-mediated genomic alterations link immunity and viral infection during human papillomavirus-driven cervical carcinogenesis. Biosci Trends 11: 383-388, 2017.

6. Sen P, Ganguly P and Ganguly N: Modulation of DNA methylation by human papillomavirus E6 and E7 oncoproteins in cervical cancer. Oncol Lett 15: 11-22, 2018.

7. Senapati R, Senapati NN and Dwibedi B: Molecular mechanisms of HPV mediated neoplastic progression. Infect Agent Cancer 11: 59, 2016.

8. Steenbergen RD, Snijders PJ, Heideman DA and Meijer CJ: Clinical implications of (epi)genetic changes in HPV-induced cervical precancerous lesions. Nat Rev Cancer 14: 395-405, 2014.

9. Morel A, Baguet A, Perrard J, Demeret C, Jacquin E, Guenat D, Mougin C and Prétet JL: 5azadC treatment upregulates miR-375 level and represses HPV16 E6 expression. Oncotarget 8: 46163-46176, 2017.

10. Fernandes JV, de Medeiros Fernandes TA, de Azevedo JC, Cobucci RN, de Carvalho MG, Andrade VS and de Araújo JM: Link between chronic inflammation and human papillomavirus-induced carcinogenesis (Review). Oncol Lett 9: 1015-1026, 2015.

11. Soto D, Song C and McLaughlin-Drubin ME: Epigenetic alterations in human papillomavirus-associated cancers. Viruses 9: 248, 2017

12. Durzynska J, Lesniewicz K and Poreba E: Human papillomaviruses in epigenetic regulations. Mutat Res Rev Mutat Res 772: 36-50, 2017.

13. Amaro-Filho SM, Pereira Chaves CB, Felix SP, Basto DL, de Almeida LM and Moreira MAM: HPV DNA methylation at the early promoter and E1/E2 integrity: A comparison between HPV16, HPV18 and HPV45 in cervical cancer. Papillomavirus Res 5: 172-179, 2018.

14. Jacquin E, Baraquin A, Ramanah R, Carcopino X, Morel A, Valmary-Degano S, Bravo IG, de Sanjosé S, Riethmuller D, Mougin C and Prétet JL: Methylation of human papillomavirus type $16 \mathrm{CpG}$ sites at E2-binding site 1 (E2BS1), E2BS2, and the Spl-binding site in cervical cancer samples as determined by high-resolution melting analysis-PCR. J Clin Microbiol 51: 3207-3215, 2013.

15. Loscalzo J and Handy DE: Epigenetic modifications: Basic mechanisms and role in cardiovascular disease $(2013 \mathrm{Grover}$ Conference series). Pulm Circ 4: 169-174, 2014.

16. Shamsi MB, Firoz AS, Imam SN, Alzaman N and Samman MA: Epigenetics of human diseases and scope in future therapeutics. J Taibah Univ Med Sci 212: 205-211, 2017.

17. Vogt G: Facilitation of environmental adaptation and evolution by epigenetic phenotype variation: Insights from clonal, invasive, polyploid, and domesticated animals. Environ Epigenet 3: dvx002, 2017.

18. Marsit CJ: Influence of environmental exposure on human epigenetic regulation. J Exp Biology 218: 71-79, 2015.

19. Li Y and Tollefsbol TO: Age-related epigenetic drift and phenotypic plasticity loss: Implications in prevention of age-related human diseases. Epigenomics 8: 1637-1651, 2016.

20. Zannas AS and Chrousos GP: Epigenetic programming by stress and glucocorticoids along the human lifespan. Mol Psychiatry 22: 640-646, 2017.

21. Osborne A: The role of epigenetics in human evolution. Biosc Horizons 10: hzx007, 2017.

22. Stefansson OA and Esteller M: Epigenetic modifications in breast cancer and their role in personalized medicine. Am J Pathol 183: 1052-1063, 2013

23. Llinàs-Arias $\mathrm{P}$ and Esteller $\mathrm{M}$ : Epigenetic inactivation of tumor suppressor coding and non-coding genes in human cancer: An update. Open Biol 7: 170152, 2017.

24. Ramassone A, Pagotto S, Veronese A and Visone R: Epigenetics and microRNAs in cancer. Int J Mol Sci 19: 459, 2018.

25. Kurdyukov S and Bullock M: DNA methylation analysis: Choosing the right method. Biology (Basel) 5: 3, 2016.

26. Zhang X, Hu M, Lyu X, Li C, Thannickal VJ and Sanders YY: DNA methylation regulated gene expression in organ fibrosis. Biochim Biophys Acta Mol Basis Dis 1863: 2389-2397, 2017.

27. Yang X, Han H, de Carvalho DD, Lay FD, Jones PA and Liang G: Gene body methylation can alter gene expression and is a therapeutic target in cancer. Cancer Cell 26: 577-590, 2014. 
28. Jin Z and Liu Y: DNA methylation in human diseases. Genes Dis 5: 1-8, 2018.

29. Moore LD, Le T and Fan G: DNA Methylation and its basic function. Neuropsychopharmacology 38: 23-38, 2013.

30. Ehrlich M: DNA hypomethylation in cancer cells. Epigenomics 1: 239-259, 2009

31. Yang HJ: Aberrant DNA methylation in cervical carcinogenesis. Chin J Cancer 32: 42-48, 2013.

32. Lu Q, Ma D and Zhao S: DNA methylation changes in cervical cancers. Methods Mol Biol 863: 155-176, 2012.

33. Liu G: $\mathrm{CDH} 1$ promoter methylation in patients with cervical carcinoma: A systematic meta-analysis with trial sequential analysis. Future Oncol 14: 51-63, 2018.

34. Snoek BC, Splunter AP, Bleeker MC, Ruiten MC, Heideman DA, Rurup WF, Verlaat W, Schotman H, Gent MV, Trommel NE and Steenbergen RD: Cervical cancer detection by DNA methylation analysis in urine. Sci Rep 9: 3088, 2019.

35. McCormick TM, Canedo NH, Furtado YL, Silveira FA, de Lima RJ, Rosman AD, Almeida Filho GL and Carvalho Mda G: Association between human papillomavirus and Epstein-Barr virus DNA and gene promoter methylation of RB1 and CDH1 in the cervical lesions: A transversal study. Diagn Pathol 10: 59, 2015

36. Cardoso MF, Castelletti CH, Lima-Filho JL, Martins DB and Teixeira JA: Putative biomarkers for cervical cancer: SNVs, methylation and expression profiles. Mutat Res 773: 161-173, 2017.

37. Fernandes JV, Araújo JM and Fernandes TA: Biology and natura history of human papillomavirus infection. Open Access J Clin Trials 2013: 5, 2013

38. Bashaw AA, Leggatt GR, Chandra J, Tuong ZK and Frazer IH: Modulation of antigen presenting cell functions during chronic HPV infection. Papillomavirus Res 4: 58-65, 2017.

39. Yang M, Wang M, Li X, Xie Y, Xia X, Tian J, Zhang K and Tang A: Wnt signaling in cervical cancer? J Cancer 9: 1277-1286, 2018 .

40. Ayala-Calvillo A, Mojica-Vázquer LH, García-Carrancá A and González-Maya L: Wnt/ $\beta$-catenin pathway activation and silencing of the APC gene in HPV-positive human cervical cancer-derived cells. Mol Med Rep 17: 200-208, 2018.

41. Lee J and Kim SS: The function of p27 KIP1 during tumor development. Exp Mol Med 41: 765-771, 2009.

42. Qi Q, Ling Y, Zhu M, Zhou L, Wan M, Bao Y and Liu Y: Promoter region methylation and loss of protein expression of PTEN and significance in cervical cancer. Biomed Rep 2: 653-658, 2014.

43. Li JY, Huang T, Zhang C, Jiang DJ, Hong QX, Ji HH, Ye M and Duan SW: Association between RASSF1A promoter hypermethylation and oncogenic HPV infection status in invasive cervical cancer: A meta-analysis. Asian Pac J Cancer Prev 16: 5749-754, 2015.

44. Sherr CJ and Bartek J: Cell cycle-targeted cancer therapies. Ann Rev Cancer Biol 1: 41-57, 2017.

45. Li X, Tao L, Tan Q, Dong Y, Pan X, Pang L, Qi Y, Zou H, Liang W, Liu W, et al: $\mathrm{CpG}$ island methylation of the CADM1 gene correlates with cervical carcinogenesis in the Uighur and Han populations of Xinjiang, China. Int J Clin Exp Pathol 9: 6977-6987, 2016

46. Holubeková V, Mendelová A, Grendár M, Meršaková S, Kapustová I, Jašek K, Vaňochová A, Danko J and Lasabová Z: Methylation pattern of $\mathrm{CDH} 1$ promoter and its association with $\mathrm{CDH} 1$ gene expression in cytological cervical specimens. Oncol Lett 12: 2613-2621,2016

47. Siegel EM, Riggs BM, Delmas AL, Koch A, Hakam A and Brown KD: Quantitative DNA methylation analysis of candidate genes in cervical cancer. PLoS One 10: e0122495, 2015.

48. Lorincz AT: Virtues and weaknesses of DNA methylation as a test for cervical cancer prevention. Acta Cytol 60: 501-512, 2016

49. Kim MK, Lee IH, Lee KH, Lee YK, So KA, Hong SR, Hwang CS, Kee MK, Rhee JE, Kang C, et al: DNA methylation in human papillomavirus-infected cervical cells is elevated in high-grade squamous intraepithelial lesions and cancer. J Gynecol Oncol 27: e14, 2016.

50. Chang CC, Huang RL, Wang HC, Liao YP, Yu MH and Lai HC: High methylation rate of LMX1A, NKX6-1, PAX1, PTPRR SOX1, and ZNF582 genes in cervical adenocarcinoma. Int J Gynecol Cancer 24: 201-209, 2014.

51. Xu L, Xu J, Hu Z, Yang B, Wang L, Lin X, Xia Z, Zhang Z and Zhu Y: Quantitative DNA methylation analysis of paired box gene 1 and LIM homeobox transcription factor $1 \alpha$ genes in cervical cancer. Oncol Lett 15: 4477-4484, 2018

52. Flamini MI, Gauna GV, Sottile ML, Nadin BS, Sanchez AM and Vargas-Roig LM: Retinoic acid reduces migration of human breast cancer cells: Role of retinoic acid receptor beta. J Cell Mol Med 18: 1113-1123, 2014.
53. Yin FF, Wang N, Bi XN, Yu X, Xu XH, Wang YL, Zhao CQ, Luo B and Wang YK: Serine/threonine kinases 31(STK31) may be a novel cellular target gene for the HPV16 oncogene E7 with potential as a DNA hypomethylation biomarker in cervical cancer. Virol J 13: 60, 2016.

54. Molano M, Moreno-Acosta P, Morales N, Burgos M, Buitrago L, Gamboa O, Alvarez R, Garland SM, Tabrizi SN, Steenbergen RD and Mejía JC: Association between type-specific HPV infections and hTERT DNA methylation in patients with invasive cervical cancer. Cancer Genomics Proteomics 13: 483-491, 2016

55. Johannsen E and Lambert PF: Epigenetics of human papillomaviruses. Virology 445: 205-212, 2013.

56. Simanaviciene V, Popendikyte V, Gudleviciene Z and Zvirbliene A: Different DNA methylation pattern of HPV16, HPV18 and HPV51 genomes in asymptomatic HPV infection as compared to cervical neoplasia. Virology 484: 227-233, 2015.

57. Wang W, Sun Z, Liu J, Wang G, Lu Z, Zhou W, Qi T and Ruan Q: Increased methylation of human papillomavirus type $16 \mathrm{DNA}$ is associated with the severity of cervical lesions in infected females from northeast China. Oncol Lett 13: 3809-3816, 2017.

58. McBride AA and Warburton A: The role of integration in oncogenic progression of HPV-associated cancers. PLoS Pathog 13 e1006211, 2017

59. Vinokurova $\mathrm{S}$ and von Knebel Doeberitz M: Differential methylation of the HPV 16 upstream regulatory region during epithelial differentiation and neoplastic transformation. PLoS One 6: e24451, 2011.

60. McBride AA: The papillomavirus E2 proteins. Virology 445: 57-79, 2013

61. Filho SM, Bertoni N, Brant AC, Vidal JP, Felix SP, Cavalcanti SM, Carestiato FN, Martins LF, Almeida LM and Moreira MA: Methylation at 3'LCR of HPV16 can be affected by patient age and disruption of E1 or E2 genes. Virus Res 232: 48-53, 2017.

62. Fertey J, Hagmann J, Ruscheweyh HJ, Munk C, Kjaer S, Huson D, Haedicke-Jarboui J, Stubenrauch F and Iftner T: Methylation of CpG 5962 in L1 of the human papillomavirus 16 genome as a potential predictive marker for viral persistence: A prospective large cohort study using cervical swab samples. Cancer Med 9: $1058-1068,2019$

63. Niyazi M, Sui S, Zhu K, Wang L, Jiao Z and Lu P: Correlation between methylation of human papillomavirus-16 L1 gene and cervical carcinoma in Uyghur women. Gynecol Obstet Invest 82: 22-29, 2017.

64. Huang J, Tan ZR, Yu J, Li H, Lv QL, Shao YY and Zhou HH: DNA hypermethylated status and gene expression of PAX1/SOX in patients with colorectal carcinoma. Onco Targets Ther 10: 4739-4751, 2017.

65. Luan T, Hua Q, Liu X, Xu P, Gu Y, Qian H, Yan L, Xu X, Geng R, Zeng $\mathrm{X}$ and Li P: PAX1 Methylation as a potential biomarker to predict the progression of cervical intraepithelial neoplasia: A Meta-analysis of related studies. Int J Gynecol Cancer 27: 1480-1488, 2017.

66. Lin YW, Tsao CM, Yu PN, Shih YL, Lin CH and Yan MD: SOX1 suppresses cell growth and invasion in cervical cancer. Gynecol Oncol 131: 174-181, 2013

67. Bowden SJ, Kalliala I, Veroniki AA, Arbyn M, Mitra A, Lathouras K, Mirabello L, Chadeau-Hyam M, Paraskevaidis E, Flanagan JM and Kyrgiou M: The use of human papillomavirus DNA methylation in cervical intraepithelial neoplasia: A systematic review and meta-analysis. EBioMedicine 50: 246-59, 2019.

68. Torres-Rojas FI, Alarcón-Romero LC, Leyva-Vázquez MA, Ortiz-Ortiz J, Mendoza-Catalán MÁ, Hernández-Sotelo D, Moral-Hernández OD, Rodríguez-Ruiz HA, Leyva-Illades D, Flores-Alfaro E and Illades-Aguiar B: Methylation of the L1 gene and integration of human papillomavirus 16 and 18 in cervical carcinoma and premalignant lesions. Oncol Lett 15: 2278-2286, 2018

69. Clarke MA, Gradissimo A, Schiffman M, Lam J, Sollecito CC Fetterman B, Lorey T, Poitras N, Raine-Bennett TR, Castle PE, et al: Human papillomavirus DNA methylation as a biomarker for cervical precancer: Consistency across 12 genotypes and potential impact on management of HPV-positive women. Clin Cancer Res 24: 2194-2202, 2018.

70. Shestakova EA and Nakatani Y: Characterization of histone predeposition complexes from different cellular compartments. J Investig Genomics 2: 25-28, 2015.

71. Bornelöv S, Reynolds N, Xenophontos M, Gharbi S, Johnstone E, Floyd R, Ralser M, Signolet J, Loos R, Dietmann S, et al: The nucleosome remodeling and deacetylation complex modulates chromatin structure at sites of active transcription to fine-tune gene expression. Mol Cell 71: 56-72.e4, 2018. 
72. Feng T, Wang H, Su H, Lu H, Yu L, Zhang X, Sun H and You Q Novel N-hydroxyfurylacrylamide-based histone deacetylase (HDAC) inhibitors with branched CAP group (Part 2). Bioorg Med Chem 21: 5339-5354, 2013.

73. Li B, Carey M and Workman JL: The role of chromatin during transcription. Cell 128: 707-719, 2007.

74. Zhang H, Dai X, Qi Y, He Y, Du W and Pang JJ: Histone deacetylases inhibitors in the treatment of retinal degenerative diseases: Overview and perspectives. J Ophthalmol 2015: 250812, 2015

75. Song C, Zhu S, Wu C and Kang J: Histone deacetylase (HDAC) 10 suppresses cervical cancer metastasis through inhibition of matrix metalloproteinase (MMP) 2 and 9 expression. J Biol Chem 288: 28021-2833, 2013.

76. Kondo Y, Shen L, Cheng AS, Ahmed S, Boumber Y, Charo C, Yamochi T, Urano T, Furukawa K, Kwabi-Addo B, et al: Gene silencing in cancer by histone $\mathrm{H} 3$ lysine 27 trimethylation independent of promoter DNA methylation. Nat Genet 40: 741-750, 2008.

77. Hiragami-Hamada K, Xie SQ, Saveliev A, Uribe-Lewis S, Pombo A and Festenstein R: The molecular basis for stability of heterochromatin-mediated silencing in mammals. Epigenetics Chromatin 2: 14, 2009.

78. Scarpini CG, Groves IJ, Pett MR, Ward D and Coleman N: Virus transcript levels and cell growth rates after naturally occurring HPV16 integration events in basal cervical keratinocytes. J Pathol 233: 281-293, 2014.

79. Yeo-Teh NSL, Ito Y and Jha S: High-Risk human papillomaviral oncogenes E6 and E7 target key cellular pathways to achieve oncogenesis. Int J Mol Sci 19: 1706, 2018.

80. Uchida C: Roles of pRB in the regulation of nucleosome and chromatin structures. Biomed Res Int 2016: 5959721, 2016.

81. Fischer M: Census and evaluation of p53 target genes. Oncogene 36: 3943-3956, 2017

82. Zhang Y, Dakic A, Chen R, Dai Y, Schlegel R and Liu X: Direct HPV E6/Myc interactions induce histone modifications, Pol II phosphorylation, and hTERT promoter activation. Oncotarget 8: 96323-96339, 2017.

83. Johansson C, Jamal Fattah T, Yu H, Nygren J, Mossberg AK and Schwartz S: Acetylation of intragenic histones on HPV16 correlates with enhanced HPV16 gene expression. Virology 482: 244-259, 2015

84. Zhang L, Yuan C, Wang Y and Zhao S: Histone deacetylases 3 (HDAC3) is highly expressed in cervical cancer and inhibited by siRNA. Int J Clin Exp Pathol 9: 3600-3605, 2016.

85. Chen X, Loo JX, Shi X, Xiong W, Guo Y, Ke H, Yang M, Jiang Y, Xia S, Zhao M, et al: E6 protein expressed by high-risk HPY activates super-enhancers of the EGFR and c-MET oncogenes by destabilizing the histone demethylase KDM5C. Cancer 78 $1418-1430,2018$.

86. Wang WT, Han C, Sun YM, Chen TQ and Chen YQ: Noncoding RNAs in cancer therapy resistance and targeted drug development. J Hematol Oncol 12: 55, 2019.

87. Sadri Nahand J, Moghoofei M, Salmaninejad A, Bahmanpour Z, Karimzadeh M, Nasiri M, Mirzaei HR, Pourhanifeh MH, Bokharaei-Salim F, Mirzaei H and Hamblin MR: Pathogenic role of exosomes and microRNAs in HPV-mediated inflammation and cervical cancer: A review. Int J Cancer 146: 305-320, 2020.

88. Łaniewski P, Cui H, Roe DJ, Barnes D, Goulder A, Monk BJ, Greenspan DL, Chase DM and Herbst-Kralovetz MM: Features of the cervicovaginal microenvironment drive cancer biomarker signatures in patients across cervical carcinogenesis. Sci Rep 9: 7333, 2019.

89. Gupta SM and Mania-Pramanik J: Retraction note: Molecular mechanisms in progression of HPV-associated cervical carcinogenesis. J Biomed Sci 26: 50, 2019.

90.Zheng ZM and Wang X: Regulation of cellular miRNA expression by human papillomaviruses. Biochim Biophys Acta 26 : 668-677, 2011.

91. Liu Z, Luo S, Wu M, Huang C, Shi H and Song X: LncRNA GHET1 promotes cervical cancer progression through regulating AKT/mTOR and Wnt/ $\beta$-catenin signaling pathways. Biosci Rep 40: BSR20191265, 2020.

92. Fouad YA and Aanei C: Revisiting the hallmarks of cancer. Am J Cancer Res 7: 1016-1036, 2017.

93. Oliveto S, Mancino M, Manfrini N and Biffo S: Role of microRNAs in translation regulation and cancer. World J Biol Chem 8: 45-56, 2017

94.Zamani S, Sohrabi A, Hosseini SM, Rahnamaye-Farzami M and Akbari A: Deregulation of miR-21 and miR-29a in cervical cancer related to HPV infection. Microrna 8: 110-115, 2019.
95. Vaschetto LM: miRNA activation is an endogenous gene expression pathway. RNA Biol 156: 826-828, 2018.

96. Zhou K, Liu M and Cao Y: New insight into microRNA fnctions in cancer: Oncogene-microRNA-tumor suppressor gene network. Front Mol Biosci 4: 46, 2017.

97. Yeung CLA, Tsang TY, Yau PL and Kwok TT: Human papillomavirus type 16 E6 suppresses microRNA-23b expression in human cervical cancer cells through DNA methylation of the host gene C9orf3. Oncotarget 8: 12158-12173, 2017.

98. Chen AH, Qin YE, Tang WF, Tao J, Song HM and Zuo M: miR-34a and miR-206 act as novel prognostic and therapy biomarkers in cervical cancer. Cancer Cell Int 17: 63, 2017.

99. Dong P, Xiong Y, Hanley SJB, Yue J and Watari H: Musashi-2, a novel oncoprotein promoting cervical cancer cell growth and invasion, is negatively regulated by $\mathrm{p} 53$-induced miR-143 and miR-107 activation. J Exp Clin Cancer Res 36: 150, 2017.

100. Ofir M, Hacohen D and Ginsberg D: miR-15 and miR-16 are direct transcriptional targets of E2F1 that limit E2F-induced proliferation by targeting cyclin E. Mol Cancer Res 9: 440-447, 2011

101. Chen X, Cao R, Liu H, Zhang T, Yuan X and Xu S: MicroRNA$15 a-5 p$-targeting oncogene YAP1 inhibits cell viability and induces cell apoptosis in cervical cancer cells. Int J Mol Med 46: 1301-1310, 2020.

102. Zhou M, Chen X, Wu J, He X and Ren R: MicroRNA-143 regulates cell migration and invasion by targeting GOLM1 in cervical cancer. Oncol Lett 16: 6393-6400, 2018.

103. Sannigrahi MK, Sharma R, Singh V, Panda NK, Rattan V and Khullar M: Role of host miRNA Hsa-miR-139-3p in HPV-16-induced carcinomas. Clin Cancer Res 23: 3884-3895, 2017.

104. Jiang Z, Song Q, Zeng R, Li J, Li J, Lin X, Chen X, Zhang J and Zheng Y: MicroRNA-218 inhibits EMT, migration and invasion by targeting SFMBT1 and DCUN1D1 in cervical cancer. Oncotarget 7: 45622-45636, 2016.

105. Zhu L, Tu H, Liang Y and Tang D: miR-218 produces anti-tumor effects on cervical cancer cells in vitro. World J Surg Oncol 16 : 204, 2018.

106. McLaughlin-Drubin ME and Münger K: The human papillomavirus E7 oncoprotein. Virology 384: 335-344, 2009.

107. Myklebust MP, Bruland O, Fluge $\varnothing$, Skarstein A, Balteskard L and Dahl O: MicroRNA-15b is induced with E2F-controlled genes in HPV-related cancer. Br J Cancer 105: 1719-1725, 2011.

108. Liu Z, Wu M, Shi H, Huang C, Luo S and Song X: DDN-AS1miR-15a/16-TCF3 feedback loop regulates tumor progression in cervical cancer. J Cell Biochem 120: 10228-10238, 2019.

109. Cheng Y, Geng L, Zhao L, Zuo P and Wang J: Human papillomavirus E6-regulated microRNA-20b promotes invasion in cervical cancer by targeting tissue inhibitor of metalloproteinase 2. Mol Med Rep 16: 5464-5470, 2017.

110. Kong Q, Wang W and Li P: Regulator role of HPV E7 protein on miR-21 expression in cervical carcinoma cells and its functional implication. Int J Clin Exp Pathol 8: 15808-15813, 2015.

111. Cai L, Wang W, Li X, Dong T, Zhang Q, Zhu B, Zhao H and Wu S: MicroRNA-21-5p induces the metastatic phenotype of human cervical carcinoma cells in vitro by targeting the von Hippel-Lindau tumor suppressor. Oncol Lett 15: 5213-5219, 2018

112. Xu L, Xu Q, Li X and Zhang X: MicroRNA-21 regulates the proliferation and apoptosis of cervical cancer cells via tumor necrosis factor- $\alpha$. Mol Med Rep 16: 4659-4663, 2017.

113. Liu F, Zhang S, Zhao Z, Mao X, Huang J, Wu Z, Zheng L and Wang Q: MicroRNA-27b up-regulated by human papillomavirus 16 E7 promotes proliferation and suppresses apoptosis by targeting polo-like kinase 2 in cervical cancer. Oncotarget 7: 19666-19679, 2016

114. Ding H, Wu YL, Wang YX and Zhu FF: Characterization of the microRNA expression profile of cervical squamous cell carcinoma metastases. Asian Pac J Cancer Prev 15: 1675-1679, 2014

115. Park S, Lee S, Kim J, Kim G, Park KH, Kim TU, Chung D and Lee H: $\Delta$ Np63 to TAp63 expression ratio as a potential molecular marker for cervical cancer prognosis. PLoS One 14: e0214867, 2019

116. Coimbra EC, Da Conceição Gomes Leitão M, Júnior MR, De Oliveira TH, Da Costa Silva Neto J and De Freitas AC: Expression profile of microRNA-203 and its $\Delta$ Np63 target in cervical carcinogenesis: Prospects for cervical cancer screening. Anticancer Res 36: 3939-3946, 2016.

117. Mandal P, Saha SS, Sen S, Bhattacharya A, Bhattacharya NP, Bucha S, Sinha M, Chowdhury RR, Mondal NR, Chakravarty B, et al: Cervical cancer subtypes harbouring integrated and/or episomal HPV16 portray distinct molecular phenotypes based on transcriptome profiling of mRNAs and miRNAs. Cell Death Discov 5: 81, 2019. 
118. Balasubramaniam SD, Balakrishnan V, Oon CE and Kaur G: Key molecular events in cervical cancer development. Medicina (Kaunas) 55: 384, 2019.

119. Yi Y, Liu Y, Wu W, Wu K and Zhang W: The role of miR-106p-5p in cervical cancer: From expression to molecular mechanism. Cell Death Discov 4: 36, 2018.

120. Cheng Y, Guo Y, Zhang Y, You K, Li Z and Geng L: MicroRNA-106b is involved in transforming growth factor $\beta 1$-induced cell migration by targeting disabled homolog 2 in cervical carcinoma. J Exp Clin Cancer Re 35: 11, 2016.

121. Natalia MA, Alejandro GT, Virginia TJ and Alvarez-Salas LM: MARK1 is a novel target for miR-125a-5p: Implications for cell migration in cervical tumor cells. Microrna 7: 54-61, 2018.

122.Xu Y, Zhao S, Cui M and Wang Q: Down-regulation of microRNA-135b inhibited growth of cervical cancer cells by targeting FOXO1. Int J Clin Exp Pathol 8: 10294-10304, 2015.

123. Li JH, Zhang Z, Du MZ, Guan YC, Yao JN, Yu HY, Wang BJ, Wang XL, Wu SL and Li Z: MicroRNA-141-3p fosters the growth, invasion, and tumorigenesis of cervical cancer cells by targeting FOXA2. Arch Biochem Biophys 657: 23-30, 2018.

124. Zhu J and Han S: miR-150-5p promotes the proliferation and epithelial-mesenchymal transition of cervical carcinoma cells via targeting SRCIN1. Pathol Res Pract 215: 738-747, 2019.

125. Li N, Cui T, Guo W, Wang D and Mao L: miR-155-5p accelerates the metastasis of cervical cancer cell via targeting TP53INP1. Onco Targets Ther 12: 3181-3196, 2019.

126. Yang M,Zhai X, Ge T, Yang C and Lou G: miR-181a-5p promotes proliferation and invasion and inhibits apoptosis of cervical cancer cells via regulating inositol polyphosphate-5-phosphatase A (INPP5A). Oncol Res 26: 703-712, 2018.

127. Farzanehpour M, Mozhgani SH, Jalilvand S, Faghihloo E, Akhavan S, Salimi V and Azad TM: Serum and tissue miRNAs: Potential biomarkers for the diagnosis of cervical cancer. Virol J 16: 116, 2019.

128. Hou T, Ou J, Zhao X, Huang X, Huang Y and Zhang Y: MicroRNA-196a promotes cervical cancer proliferation through the regulation of FOXO1 and p27Kip1. Br J Cancer 110: 1260-1268, 2014.

129. Varghese VK, Shukla V, Jishnu PV, Kabekkodu SP, Pandey D, Sharan K and Satyamoorthy K: Characterizing methylation regulated miRNA in carcinoma of the human uterine cervix. Life Sci 232: 116668, 2019.

130. Zhou LL, Shen Y, Gong JM, Sun P and Sheng JH: MicroRNA-466 with tumor markers for cervical cancer screening. Oncotarget 8: 70821-70827, 2017.

131. Chu Y, Ouyang Y, Wang F, Zheng A, Bai L, Han L, Chen Y and Wang H: MicroRNA-590 promotes cervical cancer cell growth and invasion by targeting CHL1. J Cell Biochem 115: 847-853, 2014.

132. Guerrero-Gómez AO and Guerrero-Florez M: MicroRNAs asociados al Cáncer de Cuello Uterino y sus lesiones precursoras: Una revisión sistemática. Univ Salud 18: 345-363, 2016.

133. Zhang H, Lu Y, Wang S, Sheng X and Zhang S: MicroRNA-152 acts as tumor suppressor microRNA by inhibiting Krüppel-like factor 5 in human cervical cancer. Oncol Res 27: 335-340, 2019

134. Wang S, Gao B, Yang H, Liu X, Wu X and Wang W: MicroRNA-432 is downregulated in cervical cancer and directly targets FN1 to inhibit cell proliferation and invasion. Oncol Lett 18: 1475-1482, 2019.

135. Lu Y, Hu J, Sun W, Li S, Deng S and Li M: miR-29c inhibits cell growth, invasion, and migration of pancreatic cancer by targeting ITGB1. Onco Targets Ther 9: 99-109, 2015.

136. Ma L and Li LL: miR-145 contributes to the progression of cervical carcinoma by directly regulating FSCN1. Cell Transplant 28: 1299-1305, 2019

137. Duan S, Wu A, Chen Z, Yang Y, Liu L and Shu Q: miR-204 regulates cell proliferation and invasion by targeting EphB2 in human cervical cancer. Oncol Res 26: 713-723, 2018.

138. Shu L, Zhang Z and Cai Y: microRNA-204 inhibits cell migration and invasion in human cervical cancer by regulating transcription factor 12. Oncol Lett 15: 161-166, 2018

139. Li N, Guo X, Liu L, Wang L and Cheng R: Molecular mechanism of miR-204 regulates proliferation, apoptosis and autophagy of cervical cancer cells by targeting ATF2. Artif Cells Nanomed Biotechnol 47: 2529-2535, 2019.

140. Shi C and Zhang Z: MicroRNA-320 suppresses cervical cancer cell viability, migration and invasion via directly targeting FOXM1. Oncol Lett 14: 3809-3816, 2017.

141. Hong H, Zhu H, Zhao S, Wang K, Zhang N, Tian Y, Li Y, Wang Y, Lv X, Wei T, et al: The novel circCLK3/miR-320a/FoxM1 axis promotes cervical cancer progression. Cell Death Dis 10: 950, 2019.
142. Cao XM: Role of miR-337-3p and its target Rap1A in modulating proliferation, invasion, migration and apoptosis of cervical cancer cells. Cancer Biomark 24: 257-267, 2019.

143. Hua FF, Liu SS, Zhu LH, Wang YH, Liang X, Ma N and Shi HR: miRNA-338-3p regulates cervical cancer cells proliferation by targeting MACC1 through MAPK signaling pathway. Eur Rev Med Pharmacol Sci 21: 5342-5352, 2017.

144. Lu R, Yang Z, Xu G and Yu S: miR-338 modulates proliferation and autophagy by PI3K/AKT/mTORsignaling pathwayincervicalcancer. Biomed Pharmacother 105: 633-644, 2018.

145. Jayamohan S, Kannan M, Moorthy RK, Rajasekaran N, Jung HS, Shin YK and Arockiam AJ: Dysregulation of miR-375/AEG-1 axis by human papillomavirus 16/18-E6/E7 promotes cellular proliferation, migration, and invasion in cervical cancer. Front Oncol 9: 847, 2019.

146. Shang A, Zhou C, Bian G, Chen W, Lu W, Wang W and Li D: miR-381-3p restrains cervical cancer progression by downregulating FGF7. J Cell Biochem 120: 778-789, 2019.

147. Teng P, Jiao Y, Hao M and Tang X: microRNA-383 suppresses the PI3K-AKT-MTOR signaling pathway to inhibit development of cervical cancer via down-regulating PARP2. J Cell Biochem 119: 5243-5252, 2018.

148. Wang S, Zhang Y, Yuan S and Ji X: MicroRNA-485 targets MACC1 and inhibits cervical cancer cell proliferation and invasion. Mol Med Rep 18: 2407-2416, 2018.

149. Lv M, Ou R, Zhang Q, Lin F, Li X, Wang K and Xu Y: MicroRNA-664 suppresses the growth of cervical cancer cells via targeting c-Kit. Drug Des Devel Ther 13: 2371-2379, 2019.

150. Xu J, Wan X,Chen X,Fang Y, Cheng X, Xie X and Lu W: miR-2861 acts as a tumor suppressor via targeting EGFR/AKT2/CCND1 pathway in cervical cancer induced by human papillomavirus virus 16 E6. Sci Rep 6: 28968, 2016.

151. Jin Y,Zhou X, Yao X,Zhang Z, Cui M and Lin Y: MicroRNA-612 inhibits cervical cancer progression by targeting NOB1. J Cell Mol Med 24: 3149-3156, 2020.

152. Zhang JJ, Wang DD, Du CX and Wang Y: Long noncoding RNA ANRIL promotes cervical cancer development by acting as a sponge of miR-186. Oncol Res 26: 345-352, 2018.

153. Liu S, Song L, Yao H, Zhang L, Xu D, Gao F and Li Q: miR-375 is epigenetically downregulated by HPV-16 E6 mediated DNMT1 upregulation and modulates EMT of cervical cancer cells by suppressing lncRNA MALAT1. PLoS One 11: e0163460, 2016.

154. Song H, Liu Y, Jin X, Liu Y, Yang Y, Li L, Wang X and Li G: Long non-coding RNA LINC01535 promotes cervical cancer progression via targeting the miR-214/EZH2 feedback loop J Cell Mol Med 23: 6098-6111, 2019.

155. Sun NX, Ye C, Zhao Q, Zhang Q, Xu C, Wang SB, Jin ZJ, Sun SH, Wang $\mathrm{F}$ and $\mathrm{Li} \mathrm{W}$ : Long noncoding RNA-EBIC promotes tumor cell invasion by binding to EZH2 and repressing E-cadherin in cervical cancer. PLoS One 9: e100340, 2014

156. He H, Liu X, Liu Y, Zhang M, Lai Y, Hao Y, Wang Q, Shi D, Wang N, Luo XG, et al: Human papillomavirus E6/E7 and long noncoding RNA TMPOP2 mutually upregulated gene expression in cervical cancer cells. J Virol 93: e01808-e18, 2019.

157. Ma Z, Shuai Y, Gao X, Wen X and Ji J: Circular RNAs in the tumour microenvironment. Mol Cancer 19: 8, 2020.

158. Bach DH, Lee SK and Sood AK: Circular RNAs in Cancer. Mol Ther Nucleic Acids 16: 118-129, 2019.

159. Zhao J, Lee EE, Kim J, Yang R, Chamseddin B, Ni C, Gusho E, Xie Y, Chiang CM, Buszczak M, et al: Transforming activity of an oncoprotein-encoding circular RNA from human papillomavirus. Nat Commun 10: 2300, 2019.

160. Ji F, Du R, Chen T, Zhang M, Zhu Y, Luo X and Ding Y: Circular RNA circSLC26A4 accelerates cervical cancer progression via miR-1287-5p/HOXA7 axis. Mol Ther Nucleic Acids 19 413-420, 2020.

161. Chen RX, Liu HL, Yang LL, Kang FH, Xin LP, Huang LR, Guo QF and Wang YL: Circular RNA circRNA 0000285 promotes cervical cancer development by regulating FUS. Eur Rev Med Pharmacol Sci 23: 8771-8778, 2019.

162. Ding S, Huang X, Zhu J, Xu B, Xu L, Gu D and Zhang W: ADH7, miR-3065 and LINC01133 are associated with cervical cancer progression in different age groups. Oncol Lett 19: 2326-2338, 2020 .

This work is licensed under a Creative Commons Attribution-NonCommercial-NoDerivatives 4.0 International (CC BY-NC-ND 4.0) License. 